NMDA Excitotoxicity Huntington's Disease

\title{
Neuroprotective strategies for NMDAR-mediated excitotoxicity in
}

\section{Huntington's Disease}

KD Girling ${ }^{1}$, YT Wang ${ }^{1}$

${ }^{1}$ University of British Columbia, Djavad Mowafagian Centre for Brain Health \& Dept. Medicine, Vancouver, BC Canada, 2215 Wesbrook Mall, V6T 1Z3

\section{*Corresponding Author:}

Yu Tian Wang, Ph.D., M.D.

Dept. Medicine

Division of Neurology

Djavad Mowafagian Centre for Brain Health

2215 Wesbrook Mall

Vancouver, BC, V6T 1 Z3

Tel: 604-822-0398

Email: ytwang@brain.ubc.ca 
NMDA Excitotoxicity Huntington's Disease

\section{ABSTRACT}

BACKGROUND: Huntington's Disease (HD) is an autosomal dominant neurodegenerative disease causing severe neurodegeneration of the striatum as well as marked cognitive and motor disabilities. Excitotoxicity, caused by overstimulation of NMDA receptors (NMDARs) has been shown to have a key role in the neuropathogenesis of HD, suggesting that targeting NMDAR-dependent signaling may be an effective clinical approach for HD. However, broad NMDAR antagonists are generally poor therapeutics in clinical practice. It has been suggested that GluN2A-containing, synaptically located NMDARs activate cell survival signaling pathways, while GluN2B-containing, primarily extrasynaptic NMDARs trigger cell death signaling. A better approach to development of effective therapeutics for HD may be to target, specifically, the cell-death specific pathways associated with extrasynaptic GluN2B NMDAR activation, while maintaining or potentiating the cell-survival activity of GluN2ANMDARs.

OBJECTIVE: This review outlines the role of NMDAR-mediated excitotoxicity in HD and overviews current efforts to develop better therapeutics for HD where NMDAR excitotoxicity is the target.

METHODS: A systematic review process was conducted using the PubMed search engine focusing on research conducted in the past 5-10 years. 250 articles were consulted for the review, with key search terms including "Huntington's Disease", "excitotoxicity", "NMDAR" and "therapeutics".

RESULTS: A wide range of NMDAR excitotoxicity-based targets for HD were identified and reviewed, including targeting NMDARs directly by blocking GluN2B, extrasynaptic NMDARs and/or potentiating GluN2A, synaptic NMDARs, targeting glutamate release or uptake, or targeting specific downstream cell-death signaling of NMDARs. 
NMDA Excitotoxicity Huntington's Disease

CONCLUSION: The current review identifies NMDAR-mediated excitotoxicity as a key player in HD pathogenesis and points to various excitotoxicity-focused targets as potential future preventative therapeutics for HD.

Key words: Huntington's Disease, NMDA receptor, excitotoxicity, cell death, therapeutics

\section{Huntington's Disease}

Huntington's Disease (HD) is an autosomal-dominant, inherited neurodegenerative disease caused by a CAG expansion ( $>36$ copies) in the huntingtin gene, leading to expression of a huntingtin $(\mathrm{Htt})$ protein with an expanded polyglutamine tract near the N-terminus (Huntington's Disease Collaborative Research Group, 1992). Early symptoms of HD include cognitive disruptions and alterations in mood, later developing to dance-like motor dysfunction (chorea), substantial neurodegeneration, dementia and eventually dyskinesia (Tobin 2003). Typically, symptomatic onset of HD occurs between the ages of 35-55, with death occurring 10-15 years after onset (Hayden 1981). Age of HD onset is linked to CAG repeat length and with longer CAG repeats $(>60)$, juvenile HD may occur, with bradykinesia, rigidity, dystonia, cognitive changes and epileptic seizures, often without chorea (Huntington's Disease Collaborative Research Group, 1992). The protein huntingtin (Htt) is ubiquitously expressed throughout the body and tissues, however pathology of HD is primarily brain specific, with most profound degeneration occurring in the striatum (Vonsattel et al. 1985). GABA-ergic medium spiny neurons (MSNs), constituting about 90$95 \%$ of striatal neurons, are particularly vulnerable in HD, whereas aspiny cholinergic interneurons are relatively spared (Ferrante et al. 1987). Although neurodegeneration is most prominent in striatal MSNs, non-autonomous cell death and dysfunction can also be detected in the cerebral cortex, globus pallidus, substantia nigra, white matter and hippocampus, and there is evidence of some damage to peripheral tissues and organs, including skeletal muscle 
NMDA Excitotoxicity Huntington's Disease

(Spargo et al. 1993; Heinsen et al. 1996; Kassubek et al. 2004, (Abildtrup and Shattock 2013; Rosas et al. 2003; Ehrlich 2012). Despite a known genetic cause, treatments for HD are, at present, primarily palliative and there remains a lack of effective preventative HD therapies. Studies investigating preventative medicines for HD have targeted a wide variety of molecular mechanisms associated with cell death and dysfunction, including mitochondrial dysfunction (Tabrizi et al. 2000, Lim et al. 2008), caspase activation and cleavage (Wong et al. 2015; Graham et al. 2011; Hermel et al. 2004; Wellington et al. 2002; Carroll et al. 2011; Graham et al. 2006; Uribe et al. 2012;Graham et al. 2010) and BDNF dysregulation (Strand et al. 2007; Zuccato et al. 2010).

\section{The glutamate excitotoxicity hypothesis of $\mathrm{HD}$}

One major hypothesis as to the specific vulnerability of the striatum in HD is called the excitotoxicity hypothesis (Fan and Raymond 2007). Striatal neurons receive glutamatergic input from several sources, importantly from the cortex and thalamus which stimulated glutamate receptors on striatal MSNs. Several decades of research have demonstrated that excessive glutamatergic stimulation of these receptors via impaired uptake, enhanced glutamate release, enhanced sensitivity of the receptors or impaired downstream signaling of glutamate receptors may contribute in important ways to striatal vulnerability in HD (Schwarcz et al. 1977; DiFiglia 1990). In this review we will overview the role of NMDARs in glutamate excitotoxicity, investigate evidence for NMDAR-mediated excitotoxicity in HD pathogenesis and outline current neuroprotective strategies for HD based on the excitotoxicity hypothesis. 
NMDA Excitotoxicity Huntington's Disease

\section{NMDA Receptor physiology}

Glutamate is the primary excitatory neurotransmitter in the central nervous system (Kandel et al. 1995), exerting its actions either by activating metabotropic glutamate receptors (mGluRs) which couple to $\mathrm{G}$ proteins, or via ionotropic glutamate receptors (iGluRs), which, upon ligand binding, allow passage of cations through a receptor pore (Watkins \& Evans 1981; Dingledine et al. 1999). N-methyl D-aspartate (NMDA) receptors are the most highly studied of the iGluRs due to their importance in both normal neuron physiology and in disease pathology. To open, NMDARs require dual ligand binding of glutamate and the coagonist glycine (Johnson \& Ascher 1987) as well as removal of a $\mathrm{Mg}^{2+}$ block by membrane depolarization (Mayer et al. 1984). Activation of NMDARs causes influx of $\mathrm{Ca}^{2+}$ (MacDermott et al. 1986) which activates signal transduction cascades. The slow activation and deactivation kinetics of NMDARs govern the duration of the excitatory post-synaptic potential (Lester et al. 1990), giving NMDARs an important role in synaptic strength modulation. Native NMDARs are tetrameric complexes of two GluN1 (NR1) with two GluN2 (NR2) and/or GluN3 (NR3) subunits (Benveniste \& Mayer 1991; Clements \& Westbrook 1991). Different NMDAR subunit combinations change the ion properties and pharmacology of the receptor allowing for wide functional diversity of NMDARs (Monyer et al. 1992; Ishii et al. 1993; Flint et al. 1997; Chen et al. 1999). GluN2 subunits in particular are encoded by four genes (GluN2A-D) which determine differences in NMDAR channel properties, pharmacology and distribution (Dingledine et al. 1999; Cull-Candy \& Leszkiewicz 2004). GluN2 subunits are both spatially and developmentally regulated (Monyer et al. 1992; Akazawa et al. 1994). In the forebrain of adults, the majority of NMDARs contain GluN2A and GluN2B subunits, with most NMDARs being biheteromeric GluN1-GluN2A or GluN1-GluN2B or triheteromeric GluN1-GluN2A-GluN2B receptors (Sheng et al. 1994; Li et al. 1998; Chapman et al. 2003). NMDA receptors are largely located 
NMDA Excitotoxicity Huntington's Disease

at synaptic sites, but can also found extra- or perisynaptically. During development, up to $1 / 3$ of NMDARs are extra-synaptically located, while synaptic NMDARs slowly increase in proportion as the brain matures. However a significant proportion of NMDARs remain extrasynaptic during adulthood (Tovar et al. 2013; Rosenmund et al. 1993; Cottrell et al. 2000; Petralia et al. 2010).

\section{NMDAR-mediated excitotoxicity: The role of glutamate:}

NMDARs have an important role in many neurological functions, including critical roles in synaptic plasticity, brain development and normal synaptic transmission (Aamodt \& Constantine-Paton 1999; Bliss \& Collingridge 1993). However, in many pathological conditions, overstimulation of NMDARs can trigger multiple neuronal death cascades, leading to apoptosis and necrosis (Berliocchi et al. 2005). This process is called excitotoxicity and has been implicated in a wide range of neuropathologies and neurodegenerative diseases including stroke (Lai et al. 2014. (Shiptoski 2012), Alzheimer's Disease (Hynd et al. 2004; Koutsilieri and Riederer 2007), Parkinson's Disease (Koutsilieri and Riederer 2007; Beal 1998) and neurotrauma (Marklund et al. 2004; Obrenovitch and Jutta 1997; Johnston 2005). Initial research on excitotoxicity arose from studies demonstrating that monosodium glutamate (MSG), an additive commonly found in Chinese food, was neurotoxic in the retina of the mouse (Lucas \& Newhouse 1957). Subsequent studies demonstrated that this effect was not limited to the mouse retina, and similar effects were detected in both central and peripheral nervous system neurons in several other species (Burde et al. 1971; Freedman \& Potts 1962; Olney \& Sharpe 1969). Over several decades of research, it was discovered that the primary cause of neuronal death as a result of glutamate overstimulation was a result of excessive calcium influx (Choi 1995) primarily through NMDARs (Choi et al. 1988). Subsequently, a large number of studies have investigated the 
NMDA Excitotoxicity Huntington's Disease

potential for NMDAR antagonists to protect against excitotoxic insults in various nervous system disorders, however the majority of NMDAR-antagonist studies fail to show efficacy in human clinical trials, due to multiple factors including side effects (Lipton 2004; Minnerup et al. 2012; Strokecenter.org 2016). The primary hypothesis for why NMDAR antagonists fail as therapeutics may be at least in part due to a paradoxical role of NMDARs, playing a pivotal role in both normal cellular function, including survival, and in neuronal death (Hardingham \& Bading 2003). Blockade of all neuronal NMDARs using antagonists, though effective at preventing cell death pathways associated with NMDAR-mediated excitotoxicity also block the necessary, synaptic plasticity and cell survival pathways activated by NMDAR stimulation. These studies, and others, led to research into the underlying causes of the contradictory roles of NMDARs in hopes of developing better, more specific preventative therapies for nervous system disorders where NMDAR-mediated excitotoxicity has a role.

\section{A dichotomous role of NMDARs in cell survival and cell death}

NMDARs are critical players in numerous functions related to cell survival and maintenance of neuronal homeostasis however NMDARs are also strongly involved in excitotoxic neuronal death. Although the underlying mechanisms of this dichotomous role of NMDARs is debated, there are many hypotheses as to the paradox of NMDARs. For one, the role of the NMDAR can vary depending on activity level. For example, when stimulated with low doses of NMDA, cultured granule cells show enhanced cell survival, however, with high dose stimulation with NMDA, the same neurons undergo cell death (Robert Balázs et al. 1988; Balázs et al. 1990; R. Balázs et al. 1988; Balázs et al. 1989; Didier et al. 1989; Yan et al. 1994). Similarly, cultured spinal cord neurons treated with low doses of NMDAR antagonist demonstrate enhanced cell survival, where the same neurons undergo cell death with high doses of the same antagonist (Brenneman, Forsythe, et al. 1990; Brenneman, Yu, et al. 
NMDA Excitotoxicity Huntington's Disease

1990) . This, and other similar studies prompted an early hypothesis that there may be an optimal amount of intracellular calcium, and over or under stimulation of highly calcium permeable NMDARs leads to cellular death (Choi 1995; Koike et al. 1989; Franklin \& Johnson 1992). In a similar vein, subsequent and emerging studies have demonstrated that both NMDAR location and receptor subunit composition may contribute to the differential role of the NMDAR in cell death and cell survival.

\section{The subcellular location hypothesis for NMDAR-mediated excitotoxicity}

One hypothesis for the dichotomous role of NMDARs in cell survival and cell death is that different populations of NMDARs may trigger different downstream signaling pathways upon activation. Many proteins with significant roles in molecular signaling and scaffolding are located exclusively at the synapse, such as PSD-95. Thus, it is likely that synapticallylocated NMDARs, interacting with synapse-specific proteins, may behave differently than NMDARs located peri- or extrasynaptically. Many studies have demonstrated differences in downstream signaling pathways of synaptically located NMDARs compared to extrasynaptic NMDARs, prompting a theory of excitotoxicity called the "subcellular location" model These studies suggest that stimulation of synaptically-located NMDARs activates signaling pathways associated with cell survival and plasticity, whereas extrasynaptic NMDARs, trigger pathways associated with neuronal death ( $\mathrm{Lu}$ et al. 2001; Hardingham \& Bading 2003). This hypothesis was initially tested by selective enhancement of either synaptic or extrasynaptic NMDAR activity (Choi et al. 1988; Lu et al. 2001; Hardingham et al. 2002; Hardingham \& Bading 2010). Synaptic NMDAR activity was enhanced pharmacologically, by blocking $\mathrm{K}^{+}$channels using 4-aminopyridine, applying NMDAR co-agonist glycine which only enhances synaptic NMDARs that are activated by presynaptically released glutamate (Lu et al. 2001) or blocking GABAergic inhibition using bicuculline (Hardingham \& Bading 
NMDA Excitotoxicity Huntington's Disease

2010), or by electrical stimulation, whereas extrasynaptic NMDARs were selectively stimulated using synaptic NMDAR blockade with MK-801, then bath application of NMDA(Hardingham \& Bading 2010). Alternatively their contribution was attenuated by using the extrasynaptic-preferential NMDAR antagonist memantine (Xia et al. 2010; Parsons \& Raymond 2014). Synaptic NMDARs stimulation causes a calcium-dependent upregulation of several pro-survival genes, including several anti-apoptotic factors, and suppression of several genes involved in cell death, leading to enhanced neuroprotection, reduced apoptotic ability and stimulating innate antioxidative properties of the cell (Hardingham et al. 2002; Hardingham \& Bading 2010; Parsons \& Raymond 2014). This synapse-specific NMDAR activity subsequently drives many cell-survival pathways, including extracellular signalrelated kinase 1/2 activation, cAMP response elevated-binding protein (CREB) phosphorylation and enhanced expression of brain-derived neurotrophic factor (BDNF) (Hardingham et al. 2002; Hardingham \& Bading 2010; Xu et al. 2009). On the contrary, specific stimulation of extrasynaptic NMDARs activates several molecular pathways that drive cell death, including CREB shut off, ERK1/2 inactivation and enhanced gene expression and activation of pro-apoptotic proteins such as Forkhead box protein $\mathrm{O}$ (Hardingham et al. 2002; Hardingham \& Bading 2010; Xu et al. 2009). Similarly, calpains are differentially regulated by synaptic and extrasynaptic NMDARs. Synaptic NMDARs lead to activation of $\mu$-calpain, whereas extrasynaptic NMDARs specifically activate m-calpain (Wang et al. 2013; Parsons \& Raymond 2014)'. m-calpain is preferentially involved in the cleavage of striatal-enriched tyrosine phosphatase (STEP), which subsequently activates p38 mitogen-activated protein kinase (p38MAPK) resulting in increased cell death (Hardingham et al. 2002; Hardingham \& Bading 2010; Xu et al. 2009). In line with this data, stimulation of synaptic NMDA receptors is neuroprotective against neuronal insult caused by starvation or staurosporine (Hardingham et al. 2002; Papadia et al. 2005) whereas global NMDAR 
NMDA Excitotoxicity Huntington's Disease

stimulation leads to neuronal death (Hardingham et al. 2002; Gouix et al. 2009; Zhang et al. 2007).

Synaptic and extrasynaptic NMDARs have also been shown to have opposite roles in regulation of synaptic plasticity ( $\mathrm{Lu}$ et al. 2001). It is well known that NMDARs have an essential role in both long term potentiation (LTP) and long term depression (LTD), however recent data has demonstrated that increasing extracellular glutamate leads to impairments in LTP (Izumi et al. 2008; Katagiri et al. 2001; Li et al. 2011), an effect that was reversible using NMDAR antagonists ((Izumi et al. 2008; Katagiri et al. 2001; Li et al. 2011). Similarly pre-blockade of synaptic NMDARs before bath NMDA application leads to LTD formation (Liu et al. 2013). These, and other data, suggest that synaptic NMDARs may be preferentially involved in LTP formation, whereas extrasynaptic NMDARs are necessary to facilitate LTD. Taken together, a wide range of data suggests that subcellular location of NMDARs may have large impact on the differential effects of these receptors with synaptic NMDARs preferentially involved in neuron survival machinery, and extrasynaptic NMDARs facilitating neuronal death.

\section{The subunit hypothesis of NMDAR-mediated excitotoxicity:}

Another hypothesis for the paradoxical effects of NMDARs suggests that the physiological makeup of NMDARs contributes to the differential effects of the receptor. Most NMDARs are composed of two essential GluN1 subunit(Moriyoshi et al. 1991; Yamazaki et al. 1992) and two GluN2 subunits(Kutsuwada et al. 1992; Yamazaki et al. 1992; Mori \& Mishina 1996). Variations in the GluN2 subunit leads to variations in receptor kinetics, properties and downstream signaling pathways due to difference in the carboxy-terminus of the receptor (Groc et al. 2006; Martel et al. 2009; Sanz-Clemente et al. 2013). Similar to the location hypothesis of NMDAR-mediated excitotoxicity, it has been proposed that subunit 
NMDA Excitotoxicity Huntington's Disease

composition of NMDARs may underlie differential effects of NMDARs on cell survival and cell death. Using recently developed agonists and antagonists for GluN2A- and GluN2Bcontaining NMDARs, as well as genetic deletion of receptor subtypes, researchers have been able to investigate the particular role of each receptor subtype on neuron function, as well as the role in neuron survival vs death, and as a result, there has been support for a hypothesis that GluN2A-containing NMDARs have a primary role in cell survival signaling, whereas GluN2B-containing NMDARs are largely involved in cell death signaling (Liu et al. 2007; Zhou \& Baudry 2006; DeRidder et al. 2006). Using specific antagonists for GluN2A or GluN2B-containing NMDARs, it has been shown that specific stimulation of GluN2Bcontaining NMDARs triggers excitotoxic neuronal death and apoptotic cascades, while stimulation of GluN2A-containing NMDARs is neuroprotective both in vitro against NMDA and non NMDAR-mediated neuronal death, as well as in vivo (Liu et al. 2007; Terasaki et al. 2010; Lai \& Wang 2010) Similarly, specific stimulation of GluN2A-NMDARs is associated with activation of several downstream signaling pathways associated with cell survival such as CREB (Liu et al. 2007), P13K and kinase-D-interacting substrate of $220 \mathrm{kDa}$ kinase-Dinteracting substrate of $220 \mathrm{kDa}$ (Kidins220) (López-Menéndez et al. 2009), whereas GluN2B-NMDAR stimulation activates numerous cell death specific pathways (Lai \& Wang 2010; Martin \& Wang 2010). Further, it has been shown that the subtype-specific differences in function of NMDARs are conferred by differences in the C-terminus of the NMDAR (Foster et al. 2010; Sprengel et al. 1998). To further test the differential role of NMDAR subtype on cell death and survival, Martel et al performed an experiment in which the C terminus of GluN2A was swapped with the C-terminus of GluN2B. In this experiment, the Cterminus of GluN2B enhanced neurotoxicity of the NMDAR when it replaced the GluN2A C-terminus (Martel et al. 2012), providing further evidence that GluN2B NMDARs are specifically involved in cell death, and GluN2A NMDARs enhance cell survival. 
NMDA Excitotoxicity Huntington's Disease

A controversial hypothesis of subunit-specific localization of NMDARs exists that suggests GluN2A-containing NMDARs are primarily located at synaptic sites in the forebrain, whereas GluN2B-containing NMDARs are mostly localized extra- and perisynaptically (extrasynaptic sites) (Groc et al. 2006; Martel et al. 2009). This theory works in concert with location-based theories of NMDAR-mediated excitotoxicity, suggesting that synaptic/GluN2A NMDARs lead to cell survival while extrasynaptic/GluN2B-NMDARs enhance cell death. Much evidence has supported this theory over the years (Groc et al. 2006; Sanz-Clemente et al. 2013; Martel et al. 2009; Tovar \& Westbrook 1999), however, there are several studies that have shown contradictory findings, and it is known that GluN2B can be found at synaptic sites and GluN2A can also be found outside of the synapse (Groc et al. 2006; Sanz-Clemente et al. 2013; Martel et al. 2009; Tovar \& Westbrook 1999; Petralia et al. 2010; Liu 2004; Harris \& Pettit 2007; Thomas 2006). Similarly, recent studies have shown some support for scenarios in which GluN2A, as well as synaptically located NMDARs can be implicated in cell death signaling under specific conditions (Papouin et al. 2012; Wroge et al. 2012; Zhou et al. 2013). These findings and others make the generation of a unified hypothesis for location and subcellular hypotheses of NMDAR-mediated excitotoxicity difficult to confirm. Similarly, variables such as the lack of very precise inhibitors for GluN2A and GluN2B, developmental changes in NMDAR subtype expression, growing knowledge of the importance of heterotetrameric NMDARs containing both GluN2A and GluN2B (Tovar et al. 2013) and the fact that a disproportionate percentage of NMDARS in cultured neurons are extrasynaptically located (Xia et al. 2010; Gladding \& Raymond 2011) lead to challenges in determining the true underlying cause for differences in NMDARs in controlling cell survival and cell death. 
NMDA Excitotoxicity Huntington's Disease

Based on a wide breadth of research on potential causes for dichotomy in NMDARs, it is likely that a combination of subtype, subcellular location, developmental stage and type of activation lead to the varieties in NMDAR role in cell survival and cell death.

\section{NMDAR-mediated excitotoxicity in Huntington's Disease}

It has been widely demonstrated that NMDAR-mediated excitotoxicity has a critical role in the pathogenesis of Huntington's Disease (HD). Evidence in human HD patients helped drive this theory, with the discovery that postmortem HD brains demonstrate reductions in NMDAR binding sites in the striatum (Albin et al., 1990; Young et al., 1988). Subsequently, brains of presymptomatic HD patients also showed increased expression in NMDARs in striatal MSNs, and it was found that these neurons were most vulnerable to death early on in disease progression (Graveland et al., 1985). Early studies using glutamate agonists quinolinic acid (QA) or kainic acid (KA) injected into the striatum of rats and later, to primates, led to neuropathological and behavioral changes similar to those seen in HD (Coyle and Robert 1976; Beal et al. 1991; Sanberg et al. 1989; Hantraye et al. 1990; Burns et al. 1995; Ferrante et al. 1993; McGeer and McGeer 1976; Schwarcz and Coyle 1977; Sanberg et al. 1978). Striatum neurons from pre-symptomatic transgenic HD mice show enhanced sensitivity to NMDA (Levine et al. 1999; Zeron et al. 2002), larger NMDAR currents (Zeron et al. 2002; Cepeda et al. 2001; Shehadeh et al. 2006), enhanced apoptotic death after NMDA stimulation (Shehadeh et al. 2006; Fan et al. 2007), increased surface expression of NMDARs (Shehadeh et al. 2006; Fan et al. 2007; Milnerwood et al. 2010), increased calcium responses during NMDA stimulation (Tang et al. 2005), as well as larger striatal lesions after intrastriatal QA (Graham et al. 2009; Hansson et al. 2001). This enhanced NMDAR excitotoxicity in HD appears to be mediated by extrasynaptic, GluN2B-containing NMDARs. Enhanced expression of extrasynaptic GluN2B-containing NMDARs are seen in HD 
NMDA Excitotoxicity Huntington's Disease

transgenic mice (Milnerwood et al. 2010; Lipton 2004a). and a low dose memantine, blocking extrasynaptic NMDARS, is neuroprotective against neurodegeneration, synaptic dysfunction and behavioral dysfunction in mouse models of HD both in vitro and in vivo (Milnerwood et al. 2010; Lipton 2004a; Dau et al. 2014). Similarly, elevated striatal NMDAR current and excitotoxicity in primary striatum neurons and brain slices can be reversed with the GluN2B-selective antagonist ifenprodil (Zeron et al. 2002; Milnerwood et al. 2010; Fan et al. 2007; Tang et al. 2005).

Enhanced GluN2B expression and extrasynaptic localization in HD are, at least in part, regulated by enhanced forward trafficking and stabilization of GluN2B-NMDARs (Fan et al. 2007). The HTT protein has a wide variety of binding partners (Kaltenbach et al. 2007) many of which are disrupted by the presence of mHTT in HD (Zuccato et al. 2010). mHTT disrupts normal binding of HTT to PSD-95 (Sun et al. 2001) and subsequently enhances PSD-95 binding to GluN2B, believed to lead to enhanced stabilization of GluN2B NMDARs in HD (Fan et al. 2009; Milnerwood et al. 2010). mHTT-mediated impairments in clathrinmediated endocytosis (Harjes \& Wanker 2003), and endosomal receptor recycling (X. Li et al. 2009) as well as impaired phosphorylation of both mHTT and NMDARs (Gladding \& Raymond 2011, Jarabek 2003; Lan et al. 2001) may also facilitate enhanced forward trafficking of NMDARs in HD (Gladding \& Raymond 2011).

An important consequence of enhanced NMDAR-mediated excitotoxicity in HD is the activation of calcium-dependent calpain, shown to cleave NMDARs and affect receptor trafficking and diffusion between the synapse and extrasynapse (Guttmann et al. 2001; Guttmann et al. 2002). In HD, calpain activity is increased, leading to enhanced GluN2B cleavage (Cowan et al. 2008; Gafni \& Ellerby 2002). Similarly, Striatal-Enriched protein tyrosine Phosphatase (STEP) has been shown to reduce synaptic NMDAR localization by dephosphorylation of GluN2B, and STEP activation is increased in early stage HD due to 
NMDA Excitotoxicity Huntington's Disease

early increases in calcineurin activity (Paul et al. 2002). It has been recently suggested in a study using transgenic HD mice that these changes work together to enhance NMDA excitotoxic vulnerability in HD, with increased STEP61 activity leading to reductions in synaptic NMDARs while calpain cleavage of GluN2B enhances expression of extrasynaptic NMDARs (Gladding et al. 2012)

Although the striatum is the most widely studied brain area in HD, NMDAR dysfunction may also have a role in cognitive deficits in HD. Cognitive and mood disturbances are present in early stages of HD in humans and animal models, often preceding motor symptoms (Murphy et al. 2000; Van Raamsdonk 2005; Klapstein et al. 2001). Hippocampal loss is common in HD (Spargo et al. 1993; Usdin et al. 1999) and NMDARdependent hippocampal synaptic plasticity and transmission in CA1 pyramidal neurons is altered in early and presymptomatic stages in HD mice, suggesting a potential role for NMDARs in altered hippocampal function in HD (Murphy et al. 2000; Milnerwood et al. 2006; Milnerwood \& Raymond 2007; Klapstein et al. 2001). Hippocampal neurons from YAC HD mice show hyper-excitability, reversed with NMDAR antagonists as well as increased resting cytosolic $\mathrm{Ca} 2+$ (Hodgson et al. 1999). Similarly, late stages of HD are accompanied by dementia and memory loss (Hansson et al. 2001; MacDonald et al. 1993). These data suggest that NMDAR excitotoxicity may also have a role in neuronal death and dysfunction in the hippocampus in HD, contributing to cognitive decline and memory deficit in HD.

Enhanced sensitivity to NMDA in HD models is present from birth and likely is an early underlying mechanism in HD pathogenesis (Zeron et al. 2002; Cepeda et al. 2001; Zeron et al. 2002; Cepeda et al. 2001; Shehadeh et al. 2006). Conversely, in later, symptomatic disease stages, HD transgenic mice of several strains develop resistance to NMDA both in vitro (Hansson et al. 2001) and in vivo (Graham et al. 2009) which may 
NMDA Excitotoxicity Huntington's Disease

represent compensatory mechanisms in response to elevated calcium $\left(\mathrm{Ca}^{2+}\right)$, reduced spine density(Hansson et al. 2001; Sun et al. 2002) or other neurological changes.

\section{Development of novel HD therapeutics targeting NMDAR-mediated excitotoxicity}

Considering the prevalent role of NMDAR-mediated excitotoxicity in the pathogenesis of HD, many groups have investigated and given the ineffectiveness of broad NMDAR antagonists as therapeutics for excitotoxic neuronal death (Ikonomidou \& Turski 2002; Lai et al. 2014; Tymianksi 2014). A wide array of studies have investigated potential ways to target cell death, specific death after an excitotoxic event, primarily by targeting GluN2Bcontaining, extrasynaptic NMDARs and the associated downstream signaling, while preserving GluN2A, synaptic NMDAR activity and signaling pathways. The following section will outline some of the major effort

\section{Targeting NMDA receptors}

\section{Blocking GluN2B, extrasynaptic NMDAR activity}

Given the broad evidence supporting the role of GluN2B-containing, extrasynaptically located NMDARs in HD, NMDAR antagonism seems a natural goal in the development of therapeutics. Early studies investigating excitotoxic insults in stroke and neurotrauma attempted to block NMDARs using broad NMDAR antagonists. Unfortunately, these drugs led to undesirable side effects in clinical application, largely because they also block the essential, neuroprotective role of NMDARs in normal functions including synaptic plasticity and cell survival (Ikonomidou \& Turski 2002; Lipton 2004a; Lai et al. 2014, Kremer et al. 1999). Thus, developing potent and specific antagonist drugs for GluN2B-containing, extrasynaptic NMDARs is an area of intense interest. Ifenprodil and other similar drugs are a class of NMDAR antagonists showing selective, non-competitive binding for GluN2B 
NMDA Excitotoxicity Huntington's Disease

NMDARs (Williams 1993; Fischer et al. 1997; Huang 1996; Kew et al. 1996). Initial experiments demonstrated effectiveness of these GluN2B antagonists in NMDAR-mediated excitotoxic models of stroke both in vivo and in vitro (Wang \& Shuaib 2005; Liu et al. 2007; O'Donnell et al. 2006; Graham et al. 1992; Chen et al. 2008; DeRidder et al. 2006; Gotti et al. 1988) suggesting that they may be more therapeutically relevant drugs for excitotoxic conditions. Recent studies have demonstrated the potential therapeutic benefit of GluN2B antagonism in $\mathrm{HD}$, using a co-cultured system of MSNs and cortical neurons, a more physiologically relevant culture system for studying glutamatergic synapses in HD (Milnerwood et al. 2012; Kaufman et al. 2012). Enhanced whole cell and extrasynaptic NMDAR-currents, increased sensitivity to NMDA and increased cell-death specific signaling can be detected in YAC128 HD MSNs compared to wild type in this system (Milnerwood et al. 2012). However, blocking GluN2B activity in these cultures using ifenprodil protects against NMDAR insults and mHTT-mediated CREB shutoff, whereas blocking GluN2A NMDARs does not (Milnerwood et al. 2012; Zeron et al. 2002). Similarly, enhanced NMDAR currents seen in MSNs from YAC HD mice can be attenuated using ifenprodil (Zeron et al. 2002 ; Milnerwood et al. 2010), as well as toxic mHTT nuclear inclusions (Okamoto et al. 2009) suggesting that GluN2B NMDAR antagonism may help alleviated neuropathological changes in HD. Despite promising effects of GluN2B antagonists in HD and other NMDA excitotoxic disease models, there are still limitations, namely 1) potential inefficacy of GluN2B antagonism without additional potentiation of GluN2A and subsequent cell survival signaling; 2) lack of strong subunit specificity of current GluN2B antagonists; 3) restrictive therapeutic window for GluN2B antagonists alone after an excitotoxic event (Yuan et al. 2015). These may help explain these limiting results. In addition, the dose-limiting side effects of GluN2B antagonism in clinical applications of excitotoxicity (Yuan et al. 2015) and potential for negative outcomes by blocking GluN2B, which also has a role in synaptic 
NMDA Excitotoxicity Huntington's Disease

plasticity, could contribute to lack of efficacy in improving neurological outcomes. Despite promising effects of ifenprodil in the YAC128 HD model, GluN2B-specific antagonists have shown varied effects. For example, subcutaneous injections of three different GluN2B antagonists, ifenprodil, RO25,6981 and CP101,606, failed to show benefits in an R6/2 HD model in vivo (Tallaksen-Greene et al. 2010) suggesting that effective therapeutics for HD may need to expand upon GluN2B antagonism. Subsequent studies have attempted to improve efficacy of GluN2B antagonists in in vivo models of NMDAR-mediated excitotoxic neuronal death. A recent study attempted to maximize GluN2B antagonist effectiveness in ischemia based on the idea that ischemia is associated with acidification of tissues (Katsura et al. 1992) (Yuan et al. 2015; Matsumoto et al. 1990). Subsequently this study developed pH sensitive GluN2B antagonist compounds using medicinal chemistry to help limit NMDAR antagonism to ischemic tissue, while reducing effect in healthy brain (Yuan et al. 2015). These compounds provided significant neuropathological and behavioral improvements with minimal side effects (Yuan et al. 2015) suggesting that limiting GluN2B NMDAR antagonism to areas of the brain undergoing excitotoxicity may help mitigate some of the negative consequences of NMDAR antagonism, and pave the way to effective therapies.

Concurrent with GluN2B antagonism, another potential antagonism-based therapy for excitotoxicity in HD is memantine, the only current clinically-approved NMDAR antagonist. Memantine is a non-competitive NMDAR antagonist with fast on-off kinetics that, at low doses, has shown to preferentially block tonically-activated, extrasynaptically located NMDARs but not phasically activated synaptic NMDARs (Xia et al. 2010). Memantine is currently approved as a prescription medication for Alzheimer's Diseases patients, and has shown to delay onset of behavioral and cognitive symptoms in human patients (Areosa Sastre et al. 1996; Howard et al. 2012). Given the critical role of extrasynaptic NMDARs in HD pathogenesis (Parsons and Raymond 2014; Kaufman et al. 2012; Milnerwood et al. 2012), 
NMDA Excitotoxicity Huntington's Disease

researchers have investigated the potential of memantine to act as a therapeutic strategy against excitotoxicity in HD. Given at a low dose, shown to preferentially block extrasynaptic NMDARs, memantine was able to abolish the early sensitivity to NMDA seen in YAC128 HD mouse striatum in vivo (Okamoto et al. 2009; Okamoto et al. 2009). Memantine treatment also lead to motor improvement and reduced striatal loss (Okamoto et al. 2009; Milnerwood et al. 2010). More recently, memantine treatment in YAC128 HD mice was shown to also rescue synaptic dysfunction and downstream cell death signaling in HD, normalizing enhanced extrasynaptic NMDAR expression, reducing calpain activation, reducing p38 MAPK activation and rescuing CREB shutoff (Dau et al. 2014). Synaptic NMDAR activity and signaling were unaffected by low-dose memantine (Dau et al. 2014).

While broad NMDAR antagonism isn't ideal for HD therapeutic development, these studies demonstrate that disease- or area-specific GluN2B- or extrasynaptic-specific NMDAR antagonism may provide neuroprotective benefit in HD.

\section{Enhancing GluN2A, synaptic NMDAR activity}

Based on evidence demonstrating that synaptically-located, GluN2A-containing NMDARs are preferentially tied to several fundamental cell-survival pathways (Hardingham \& Bading 2003; Hardingham et al. 2002; Hardingham \& Bading 2010; Martel et al. 2012; Lai et al. 2014; Liu et al. 2007) and that blockade of GluN2A-containing NMDARs using the antagonist NVP-AAV077 significantly worsens apoptosis, cell death and behavioral outcomes in vitro or in vivo models of stroke (Liu et al. 2007) a better option may be to enhance the function of GluN2A-containing, synaptic NMDARs to improve cell survival and function after excitotoxic insults. It has been shown that brief bath application of suprasaturating doses of glycine leads to selective stimulation of synaptically located NMDARs (Man et al. 2003; Lu et al. 2001). As glycine is a co-agonist of NMDARs, bath 
NMDA Excitotoxicity Huntington's Disease

glycine application enhances activation of NMDARs selectively located in the synapse that are stimulated by spontaneous presynaptic glutamate release (Man et al. 2003; Lu et al. 2001) and not extrasynaptic NMDARs, which are not active in an unstimulated state (Man et al. 2003; Lu et al. 2001). Glycine enhancement of synaptic GluN2A-containing NMDARs leads to enhancement of cell survival signaling and reduces apoptotic cell death in in vitro NMDAR-mediated excitotoxicity (Liu et al. 2007). Similarly, in an MCAO stroke model in rats, glycine given post-stroke significantly reduced infarct size, an effect that was enhanced when animals were co-treated with GluN2B antagonist Ro-25-698 (Liu et al. 2007). One limitation of GluN2A agonism as a potential target for excitotoxic death is that there is a lack of specific, effective GluN2A agonists available. Similarly, despite many studies supporting a survival role of synaptic, GluN2A NMDARs, some studies refute this and suggest synaptic or GluN2A-containing NMDARs can also mediate cell death (Wroge et al. 2012, Papouin et al. 2012). However, based on data in excitotoxic stroke models, it is possible that compounds to enhance synaptic, GluN2A NMDARs may show neuroprotective benefit against NMDAR excitotoxicity and may be a promising next step in the search for better HD therapeutics, especially if used in conjunction with extrasynaptic GluN2B antagonism.

\section{Targeting glutamate release and uptake in $\mathrm{HD}$}

Another way in which striatum neurons may be particularly prone to NMDAR mediated excitotoxicity in HD is through impaired glutamate release and uptake. Though not observed in all mouse models ( $\mathrm{Li}$ et al. 2004), some transgenic mouse models, such as the R6/2 HD model, show increased spontaneous EPSCs in striatum MSNs in acute slices in presymptomatic animals (Cepeda et al. 2003), indicative of enhanced glutamate release. Similarly, in HD patients and transgenic HD mice, metabolites 3-hydroxykyneurine, enhancing oxidative stress or quinolinic acid, stimulating NMDARs, are both augmented 
NMDA Excitotoxicity Huntington's Disease

(Guidetti et al. 2006; Guidetti et al. 2004), further suggesting upstream changes that could enhance excitotoxic vulnerability in MSN NMDARs. Along these lines, impaired glutamate transport may also play a key role in HD excitotoxicity. Normally, glutamate transporters play an important role in preventing glutamate buildup at the synapse, reuptaking excess to prevent excitotoxicity. However, in HD, some studies have suggested that glutamate reuptake is impaired. In R6/2 HD mice, very early deficits in mRNA expression of the important glial transporter GLT-1 can be detected in both cortex and striatum tissues (Liévens et al. 2001) as well as decreased protein expression ((Faideau et al. 2010; Liévens et al. 2001). Impaired basal glutamate uptake by GLT-1 in HD mouse models has also been further reported by using microdialysis (Miller et al. 2008), measurement of impaired glutamate uptake in synaptosomes (Huang et al. 2010; Liévens et al. 2001) and D-aspartate binding (Liévens et al. 2001). Human HD brains similarly show impaired glutamate uptake using a $\left[{ }^{3} \mathrm{H}\right]$-glutamate uptake assay or measuring $\left[{ }^{3} \mathrm{H}\right]$-aspartate binding(Cross et al. 1986; Hassel et al. 2007). Subsequent studies have investigated the potential of reversing impairments in GLT-1 in HD models. The antibiotic ceftriaxone, shown to elevate expression of GLT-1, was recently used in R6/2 HD mice, given for 5 days (Miller et al. 2008). The drug effectively enhanced GLT-1 levels, reversed impaired glutamate uptake in HD animals vs wild type and led to improvements in HD phenotype (Miller et al. 2008). However, recent data using a more physiological in situ model of glutamate uptake demonstrated no impairments in glutamate clearance following synaptic release in YAC128 or R6/2 mice (Parsons et al. 2016).

\section{Targeting cell-death specific signaling of NMDARs}

Given the ineffectiveness of broad NMDAR antagonists in clinical application, a potential therapeutic strategy for NMDAR-mediated excitotoxic death focuses on downstream 
NMDA Excitotoxicity Huntington's Disease

pathways activated by NMDAR stimulation. As discussed, synaptic, GluN2A-NMDAR stimulation is specifically associated with many cell-survival signaling pathways. These pathways are antagonized during NMDAR-excitotoxicity by extrasynaptic GluN2B-NMDAR stimulation, which trigger downstream signaling associated with cell death. By developing therapeutic targets that specifically shut down cell death signaling associated with GluN2B, extrasynaptic NMDARs, the cell-survival signaling of synaptic, GluN2A NMDARs may remain intact, preventing the negative side effects of NMDAR antagonism.

\section{PSD-95}

One way in which NMDARs confer differential outcomes on cell death and cell survival is by coupling directly with different interacting proteins. By interacting with proteins located specifically at synaptic or extrasynaptic locations, NMDARs may be functionally linked to different downstream signaling pathways for cell survival or cell death. Similarly, GluN2A and GluN2B NMDARs have shown to interact preferentially with cell survival and cell death-specific signaling molecules, respectively, by differential direct coupling via the NMDAR C-terminus (Foster et al. 2010; Sprengel et al. 1998; Martel et al. 2012). These important differences have allowed scientists opportunity to develop therapeutic potential drugs for NMDAR excitotoxic conditions that aim to disrupt direct or indirect NMDAR interaction with cell-death specific molecules, such as neuronal nitric oxide synthase (nNOS) (Aarts et al. 2002; Zhou et al. 2010; Sattler and Tymianski 2000), death-associated protein kinase 1 (DAPK1) (Tu et al. 2010; Fan et al. 2014) and PTEN (Zhang et al. 2013). A particularly important target of NMDAR-mediated interaction protein studies is PSD-95, a membrane-associated guanylate cyclase (MAGUK) that is found concentrated at the postsynaptic density of glutamatergic synapses, with essential roles in synapse stabilization and plasticity (El-Husseini et al. 2000). PSD-95 binds directly to GluN2B via PDZ domains 
NMDA Excitotoxicity Huntington's Disease

(Kornau et al. 1995; Brenman et al. 1996), which has shown to facilitate excitotoxic death signaling, by linking GluN2B-NMDARs with nNOS (Aarts et al. 2002; Sattler and Tymianski 2000). mHTT has shown to exacerbate GluN2B-NMDAR interaction, with enhanced GluN2B-PSD-95 binding detected in striatal tissue from YAC transgenic HD mice at times when enhanced NMDA sensitivity is present (Fan et al. 2009), whereas this effect is gone later, when NMDA resistance occurs (Jarabek 2003). Uncoupling of PSD-95 with GluN2B using a small interfering peptide NR2B-9c (Aarts et al. 2002) reduced striatal sensitivity to NMDA to levels observed in WT MSNs (Fan et al. 2009). However, this mHTT-PSD-95-NMDAR mechanism in HD is thought to be independent of nNOS, and rather dependent on enhanced activation of p38 MAPK cell death signaling (Fan et al. 2012) as enhanced p38 MAPK can also be rescued with GluN2B-9c in HD transgenic models (Fan et al. 2012).

Another important role of PSD-95-GluN2B interaction in HD is through regulation of NMDAR trafficking and localization. PSD-95 interaction with NMDARs via the C-terminal tail has previously been shown to regulate NMDAR stabilization at synapses (Roche et al. 2001; Lin et al. 2004; Prybylowski et al. 2005). In the striatum of YAC transgenic models of HD altered NMDAR trafficking includes enhanced surface expression of NMDARs (Fan et al. 2009) as well as increased expression of PSD-95 at extrasynaptic sites (Milnerwood et al. 2010), shown to sensitize HD mice to NMDA excitotoxic cell death. Wild type huntingtin itself has also been shown to interact strongly with PSD-95 directly, linking it to NMDARs (Shirasaki et al. 2012); however, in HD, expanded polyglutamine weakens the Htt-PSD-95 interaction (Sun et al. 2001), leading to enhanced sensitivity of existing NMDARs to NMDA (Sun et al. 2001). Similarly, impaired mHTT-PSD-95 interaction increases extrasynaptic expression of PSD-95, a normally synapse-specific protein (Fan et al. 2012). Taken together, PSD-95's strong interaction with GluN2B, strengthened by the presence of mHTT is thought 
NMDA Excitotoxicity Huntington's Disease

to facilitate extrasynaptic expression of GluN2B-containing NMDARs by stabilizing them via PSD-95 (Fan et al. 2012; Parsons and Raymond 2014; Parsons et al. 2014). The NR2B-9c peptide further shows benefit to HD models by partially correcting mistaken trafficking of NMDARs, mildly reducing the enhanced surface expression of NMDARs in HD transgenic MSNs (Fan et al. 2009).

Several studies have investigated other potential ways to correct impaired PSD-95 and NMDAR localization in HD. Mislocalization of PSD-95 and extrasynaptic NMDARs in HD has been shown to be linked to post-translational modifications of NMDARs such as caspases, calpains, phosphorylation and palmitoylation (Gladding and Raymond 2011; Parsons and Raymond 2014). HD is linked with impairments in palmitoylation (Young et al. 2012; Sanders and Hayden 2015). Wild type HTT, along with its strong interaction with PSD, also interacts with the palmitoylacytransferase DHHC17, otherwise known as Huntingtin Interacting Protein 14 (HIP14) (Huang et al. 2011; Singaraja et al. 201; Sutton et al. 2013). In HD, mHTT-HIP14 interaction is impaired (Huang et al. 2011; Singaraja et al. 2011), and genetic knockout mice for HIP14 or the HIP14-like protein (HIP14L) share similar phenotypical features with HD (Singaraja et al. 2002). Palmitoylation of NMDARs can impact their surface expression and trafficking (Hayashi et al. 2009; Mattison et al. 2012), and similarly, palmitoylation of PSD-95 is important for synaptic targeting of the GluN2BPSD-95 complex (Craven et al. 1999; Parsons and Raymond 2014). Along with HD-like phenotype, Hip14-/- mice also show reduced palmitoylation of PSD-95 (Singaraja et al. 2002). Current studies are investigating the role of impaired palmitoylation in HD on PSD-95 and NMDAR expression and localization.

\section{Calpains and STEP}


NMDA Excitotoxicity Huntington's Disease

Calcium influx as a result of NMDAR stimulation activates a wide variety of downstream molecular mechanisms. Calpains, a class of calcium-dependent cysteine proteases have been shown to have a role in NMDAR-mediated HD pathogenesis. Excitotoxic NMDAR activation of calpains (Siman \& Carl Noszek 1988) has shown to have a key role in proteolysis, impaired synaptic function and neuronal damage after an NMDAR-mediated excitotoxic event (Arai et al. 1991; Lee et al. 1991; Arlinghaus et al. 1991; Lai et al. 2014; Rami \& Krieglstein 1993). NMDAR-mediated calpain activity can also cause further calcium overload after NMDAR calcium entry, due to calpain-mediated cleavage of the sodium-calcium exchanger (NCX) (Bano et al. 2005), creating enhanced cell vulnerability to calcium-mediated cell death pathways (Lai et al. 2014). Calpain activation after NMDAR excitotoxicity appears to be GluN2B-specific, triggering cell death signaling such as the 35$\mathrm{kDa}$ regulatory activator (p35) of cdk5 (Patrick et al. 1999; Lee et al. 2000), cleaving it into the toxic p25 fragment (Lee et al. 2000), and can be blocked using antagonists for GluN2B but not GluN2A (DeRidder et al. 2006;Gascón et al. 2008). Calpains are also differentially regulated by synaptic and extrasynaptic NMDARs, with synaptic NMDARs activating $\mu$ calpain while extrasynaptic NMDARs activate m-calpain (Wang et al. 2013). m-calpain in particular cleaves striatal enriched tyrosine phosphatase (STEP), which subsequently activates p38-activated mitogen activated kinase (p38MAPK) (Wang et al. 2013; Xu et al. 2009), further contributing to differential NMDAR effects (Parsons and Raymond 2014).

In mouse models of $\mathrm{HD}$, early, pre-symptomatic enhancement of calpain activation can be detected, along with a subsequent increase in the synaptic-specific STEP61 (Cowan et al. 2008; Gafni and Ellerby 2002; Gladding et al. 2012; Dau et al. 2014). Calpain and STEP61 activation significantly contributes to enhanced NMDA sensitivity in HD both by dephosphorylating the GluN2B NMDAR subunit, leading to enhanced expression of extrasynaptic and not synaptic NMDARs (Gladding et al. 2012). STEP61 also contributes to 
NMDA Excitotoxicity Huntington's Disease

neuronal death in HD by dephosphorylation and deactivation of the survival-specific proteins ERK1/2 (Gladding et al. 2014) as well as STEP33 (a cleavage product of STEP61)-mediated activation of p38 MAPK, leading to p38 activation and subsequent cell death (Gladding et al. 2014). Activated p38MAPK can be detected in the striatum of transgenic HD mice both presymptomatically during enhanced sensitivity to NMDA, and later, NMDA resistant stages (Fan et al. 2012; Saavedra et al. 2011). Inhibition of calpain has shown to reverse the enhanced extrasynaptic NMDAR expression seen in the YAC128 HD model (Gladding et al. 2012; Gladding and Raymond 2011; Parsons and Raymond 2014). Calpain effects appear to be particularly important at early stages of the disease, as enhanced calpain is only detected at early, pre-symptomatic stages (Dau et al. 2014). These data point to calpain inhibition as potential early target to prevent enhanced sensitivity to NMDA as well as prevent p38 activation in later disease stages (Gladding et al. 2012). However, calpains are ubiquitously expressed and necessary for many aspects of cell survival (Lai et al. 2014) thus they should be viewed with caution when developing therapeutics.

\section{Caspases}

A major downstream pathway associated with NMDAR-mediated excitotoxic and subsequent apoptotic death is the activation of caspases. Caspases are cysteine-aspartic proteases, activated as a part of the apoptotic cascade that act to post-translationally modify proteins by cleaving at specific sites, which may act as a gain- or loss- of function modification(Pop and Salvesen 2009). Caspases play an important role in apoptosis, and initiator caspases, activated both stress- and cell-type dependently, can initiate proteolytic caspase cascades, leading to recruitment and activation of executioner caspases and apoptotic cell death (Pop and Salvesen 2009; Graham et al. 2011). Caspase activation and apoptosis have shown to play an important role in HD pathogenesis. TUNEL staining in the affected areas of HD 
NMDA Excitotoxicity Huntington's Disease

brains (Dragunow et al. 1995), indicates that apoptotic cell death contributes to HD neuropathy (Fan and Raymond 2007 ). Similarly, activated caspase- 8 and caspase- 6 can be detected in the tissues of transgenic HD animal models, as well as in the brains of both early and late stage HD patients (Sánchez et al. 1999; Graham et al. 2006; Hodges et al. 2006; Graham et al. 2010; Hermel et al. 2004) and increased proform casp3 can be detected in later stage HD human brain tissue (Graham et al. 2010). The huntingtin protein contains several consensus sites for caspase cleavage (Wellington et al. 1998; Wellington et al. 2000) and is proteolytically cleaved by caspases in both HD and normal tissues. In HD, caspase cleavage of the mutated mHTT creates toxic fragments, shown to have a key role in HD pathogenesis both in vitro and in vivo (Graham et al. 2006; Graham et al. 2010; Wellington et al. 2002; Mangiarini et al. 1996). Caspase-mediated apoptosis in HD appears to be NMDA excitotoxicity-dependent. Cultured MSNs from transgenic YAC128 HD mice demonstrate enhanced casp6 mRNA (Graham et al. 2006) and cultured YAC42 and YAC72 HD striatum neurons have increased levels of active casp3 after NMDA stimulation (Zeron et al. 2002). Similar increases in casp3 are detected in human HD lymphoblasts when stimulated with mitochondrial stressors(Sawa et al. 1999). Using fluorescence substrate cleavage assays in vitro, it has been demonstrated that caspase activation effects in HD are mediated by the intrinsic apoptotic cascade, rather than the extrinsic death-receptor mediated pathway (Zeron et al. 2004).

Several studies have investigated the potential for caspase inhibition as a means of protecting against HD-induced neuropathologies. In cultured HD neurons, inhibition of casp3, casp6 or casp9 protects cells against NMDAR-mediated apoptotic death (Tang et al. 2005; Graham et al. 2006). Similarly, minocycline treatment, reducing casp1 and casp3 mRNA, slows HD progression in mouse HD models in vivo (Chen et al. 2000). However, casp3 inhibition alone doesn't work in all HD models (Kim et al. 1999). Casp6, in particular, has been proposed as 
NMDA Excitotoxicity Huntington's Disease

an initiator caspase in apoptotic HD cell death cascades (Graham et al. 2011). Levels of activated casp6 correlate positively with the size of the CAG repeat and inversely with age of HD onset (Graham et al. 2010). Transgenic HD mice engineered with a casp6 resistant mHTT (C6R mice) show neuroprotection against HD striatal atrophy and neurodegeneration (Graham et al. 2006). Similarly, C6R striatal neurons show neuroprotection against NMDA and staurosporine in vitro and $\mathrm{C} 6 \mathrm{R}$ mice have reduced quinolinic acid-induced striatal lesions, improved behavioral outcomes and improvements in neurological HD changes (Graham et al. 2006; Pouladi et al. 2009; Warby et al. 2008; Graham et al. 2011; Graham et al. 2010; Milnerwood et al. 2010; Wellington et al. 2002). Similarly, chemical casp6 inhibition (Graham et al. 2010), dominant-negative caspase inhibition (Hermel et al. 2004) or genetic silencing of casp6 (Uribe et al. 2012;Wong et al. 2015) are neuroprotective and behaviorally beneficial in several models of HD. These data, as well as data demonstrating early activation of casp6 in pre-symptomatic and early stage HD brains, while casp3 isn't active until later in disease progression (Graham et al. 2010) suggest that casp6 may be activated early, followed by casp3 activation, and may be a possible therapeutic target for HD (Graham et al. 2011).

\section{Conclusions}

NMDAR-mediated excitotoxicity has been shown to have a critical role in the pathogenesis of Huntington's Disease. Thus, the understanding of pathways involved in cell death after excitotoxicity is of utmost importance. Development of effective and clinically applicable drug targets for NMDAR-mediated excitotoxicity in HD have shown potential benefits in a wide range of animal models and may represent novel therapeutics for HD that are aimed at presymptomatic prevention of symptoms, rather than palliative treatments. Similarly, developing novel drugs for NMDA exitotoxicity meets a large goal in the medical 
NMDA Excitotoxicity Huntington's Disease

community as they may have wide reaching applicability to not only HD, but also use in many neurodegenerative diseases of aging and brain injury.

\section{Compliance with Ethical Guidelines:}

1) Conflict of Interest: Kimberly Girling and Yu Tian Wang declared that they have no conflict of interest.

2) Human and Animal Rights, and Informed Consent: All institutional and national guidelines for the care and use of laboratory animals were followed.

This manuscript is a review article and does not involve a research protocol requiring approval by the relevant institutional review board or ethics committee.

\section{Figure Captions:}

Figure 1: Dichotomous Role of NMDARs in cell survival and cell death.

Activation of synaptically located, primarily GluN2A-containing NMDARs is associated with a wide range of cell survival and plasticity-promoting signaling pathways. Activation of these receptors leads to increased CREB phosphorylation in the nucleus, driving transcription of a range of cell survival-promoting genes. GluN2A, synaptic NMDAR activation also activates calcium-dependent calcineurin, shown to be involved in LTP and plasticity. Similarly, synaptic, GluN2A-NMDARs promote signaling of several cell survival molecular pathways including ERK1/2, PI3K and BDNF. Conversely, extrasynaptic, primarily GluN2B-NMDARs are related to cell death signaling. These receptors inhibit many of the synaptic, GluN2A pathways, including CREB shutoff, inhibition of ERK1/2, BDNF and P13K, and signals many molecular pathways involved in cell death, including JNK, and p38 MAPK. Extrasynaptic GluN2B NMDARs also activate cleavage molecules caspase and mcalpain, involved in protein cleavage, apoptosis and cell death.

Figure 2: Schematic diagram of mHTT-dependent dysregulation in NMDAR expression and signaling in $H D$.

Increased release from cortical (or thalamic) afferents stimulates NMDARs on medium spiny neurons in the striatum. Increased release and reduced reuptake from astrocytes leads to 
NMDA Excitotoxicity Huntington's Disease

increased glutamate at the synapse, causing spillover and stimulating extrasynaptic, GluN2Bcontaining NMDARs, shown to be associated with cell death signaling. Increased NMDAR stimulation leads to increases in intracellular calcium, which stimulates increase in apoptotic signaling pathways, as well as activation of calcium-dependent molecules, such as caspases and calpains, which cleave mHTT into toxic fragments and stimulate cell death signaling. Calpain activation also leads to increased cleavage of GluN2B NMDARs, facilitating their movement from synaptic to extrasynaptic sites. $\mathrm{Ca} 2+$ also activates the calcium dependent molecule calcineurin, which subsequently activates STEP, which dephosphorylates and destabilizes synaptic NMDARs, reducing their expression. STEP also leads to the clathrin vesicle endocytosis of NMDARs, and their recycling to extasynaptic sites (not shown). mHTT influences PSD-95 interaction with NMDARs, interacting less strongly with GluN2ANMDARs in the synapse, while stabilizing GluN2B-NMDARs extrasynaptically. Increased expression and stabilization of extrasynaptic NMDARs leads to increased sensitivity to NMDA, increased cell death and apoptotic signaling and dephosphorylation of CREB in the nucleus, leading to transcriptional dysregulation.

\section{References:}

Aamodt, S.M. \& Constantine-Paton, M., 1999. The role of neural activity in synaptic development and its implications for adult brain function. Advances in neurology, 79, pp.133-144.

Aarts, M. et al., 2002. Treatment of ischemic brain damage by perturbing NMDA receptorPSD-95 protein interactions. Science, 298(5594), pp.846-850.

Abramov, E. et al., 2009. Amyloid-beta as a positive endogenous regulator of release probability at hippocampal synapses. Nature neuroscience, 12(12), pp.1567-1576.

Akazawa, C. et al., 1994. Differential expression of five N-methyl-D-aspartate receptor subunit mRNAs in the cerebellum of developing and adult rats. The Journal of comparative neurology, 347(1), pp.150-160.

Albin RL, Young AB, Penney JB, et al. Abnormalities of striatal projection neurons and N- 
NMDA Excitotoxicity Huntington's Disease

methyl-D-aspartate receptors in presymptomatic Huntington's disease. $N$ Engl J Med. 1990;322(18):1293-8.

Anon, Clinical Trials Registry | Internet Stroke Center. Available at: http://www.strokecenter.org/trials/ [Accessed November 11, 2015a].

Anon, 2013. Latest Alzheimer's Facts and Figures. Latest Facts \& Figures Report Alzheimer's Association. Available at: http://www.alz.org/facts/overview.asp [Accessed November 23, 2015].

Anon, Memantine for Enhanced Stroke Recovery - Full Text View - ClinicalTrials.gov. Available at: https:/clinicaltrials.gov/ct2/show/NCT02144584 [Accessed November 25, $2015 b]$.

Anon, 2015. WHO | The top 10 causes of death. Available at: www.who.int/mediacentre/factsheets/fs310/en [Accessed November 15, 2015].

Arai, A. et al., 1991. A brief period of hypoxia causes proteolysis of cytoskeletal proteins in hippocampal slices. Brain research, 555(2), pp.276-280.

Areosa Sastre, A., Sherriff, F. \& McShane, R., 1996. Memantine for dementia. In Reviews. Arlinghaus, L., Mehdi, S. \& Lee, K.S., 1991. Improved posthypoxic recovery with a membrane-permeable calpain inhibitor. European journal of pharmacology, 209(1-2), pp.123-125.

Babu, C.S., Saravana Babu, C. \& Ramanathan, M., 2009. Pre-ischemic treatment with memantine reversed the neurochemical and behavioural parameters but not energy metabolites in middle cerebral artery occluded rats. Pharmacology, biochemistry, and behavior, 92(3), pp.424-432.

Baker, S.J., 2007. PTEN enters the nuclear age. Cell, 128(1), pp.25-28.

Balázs, R. et al., 1989. N-methyl-D-aspartate promotes the survival of cerebellar granule cells: pharmacological characterization. Neuroscience letters, 101(3), pp.241-246. 
NMDA Excitotoxicity Huntington's Disease

Balázs, R. et al., 1988. Stimulation of the receptor has a trophic effect on differentiating cerebellar granule cells. Neuroscience letters, 87(1-2), pp.80-86.

Balázs, R., Hack, N. \& Jørgensen, O.S., 1990. Interactive effects involving different classes of excitatory amino acid receptors and the survival of cerebellar granule cells in culture. International journal of developmental neuroscience: the official journal of the International Society for Developmental Neuroscience, 8(4), pp.347-359.

Balázs, R., Jørgensen, O.S. \& Hack, N., 1988. N-methyl-d-aspartate promotes the survival of cerebellar granule cells in culture. Neuroscience, 27(2), pp.437-451.

Bano, D. et al., 2005. Cleavage of the plasma membrane $\mathrm{Na}+\mathrm{Ca} 2+$ exchanger in excitotoxicity. Cell, 120(2), pp.275-285.

Beal, M.F., 1998. Excitotoxicity and nitric oxide in Parkinson's disease pathogenesis. Annals of neurology, 44(3 Suppl 1), pp.S110-4.

Benveniste, H. et al., 1984. Elevation of the extracellular concentrations of glutamate and aspartate in rat hippocampus during transient cerebral ischemia monitored by intracerebral microdialysis. Journal of neurochemistry, 43(5), pp.1369-1374.

Benveniste, M. \& Mayer, M.L., 1991. Kinetic analysis of antagonist action at N-methyl-Daspartic acid receptors. Two binding sites each for glutamate and glycine. Biophysical journal, 59(3), pp.560-573.

Berliocchi, L., Bano, D. \& Nicotera, P., 2005. Ca2+ signals and death programmes in neurons. Philosophical transactions of the Royal Society of London. Series B, Biological sciences, 360(1464), pp.2255-2258.

Bi, X. et al., 1998. Calpain-mediated regulation of NMDA receptor structure and function. Brain research, 790(1-2), pp.245-253.

Blanchet, P.J. et al., 1999. Differing effects of N-methyl-D-aspartate receptor subtype selective antagonists on dyskinesias in levodopa-treated 1-methyl-4-phenyl- 
NMDA Excitotoxicity Huntington's Disease

tetrahydropyridine monkeys. The Journal of pharmacology and experimental therapeutics, 290(3), pp.1034-1040.

Bliss, T.V.P. \& Collingridge, G.L., 1993. A synaptic model of memory: long-term potentiation in the hippocampus. Nature, 361(6407), pp.31-39.

Bosley, T.M. et al., 1983. Effects of anoxia on the stimulated release of amino acid neurotransmitters in the cerebellum in vitro. Journal of neurochemistry, 40(1), pp.189201.

Bredt, D.S., Hwang, P.M. \& Snyder, S.H., 1990. Localization of nitric oxide synthase indicating a neural role for nitric oxide. Nature, 347(6295), pp.768-770.

Brenman, J.E. et al., 1996. Interaction of nitric oxide synthase with the postsynaptic density protein PSD-95 and alpha1-syntrophin mediated by PDZ domains. Cell, 84(5), pp.757767.

Brenneman, D.E., Forsythe, I.D., et al., 1990. N-methyl-D-aspartate receptors influence neuronal survival in developing spinal cord cultures. Brain research. Developmental brain research, 51(1), pp.63-68.

Brenneman, D.E., Yu, C. \& Nelson, P.G., 1990. Multi-determinate regulation of neuronal survival: neuropeptides, excitatory amino acids and bioelectric activity. International journal of developmental neuroscience: the official journal of the International Society for Developmental Neuroscience, 8(4), pp.371-378.

Brown, M.S. \& Goldstein, J.L., 1997. The SREBP pathway: regulation of cholesterol metabolism by proteolysis of a membrane-bound transcription factor. Cell, 89(3), pp.331-340.

Bullock, M.R. et al., 1999. An Open-Label Study of CP-101,606 in Subjects with a Severe Traumatic Head Injury or Spontaneous Intracerebral Hemorrhage. Annals of the New York Academy of Sciences, 890(1 NEUROPROTECTI), pp.51-58. 
NMDA Excitotoxicity Huntington's Disease

Burde, R.M., Schainker, B. \& Kayes, J., 1971. Acute effect of oral and subcutaneous administration of monosodium glutamate on the arcuate nucleus of the hypothalamus in mice and rats. Nature, 233(5314), pp.58-60.

Cao, J. et al., 2005. The PSD-95-nNOS interface: a target for inhibition of excitotoxic p38 stress-activated protein kinase activation and cell death. The Journal of cell biology, 168(1), pp.117-126.

Castillo, J. et al., 1996. Neuroexcitatory amino acids and their relation to infarct size and neurological deficit in ischemic stroke. Stroke; a journal of cerebral circulation, 27(6), pp.1060-1065.

Cepeda, C. et al., 2001. Differential sensitivity of medium- and large-sized striatal neurons to NMDA but not kainate receptor activation in the rat. The European journal of neuroscience, 14(10), pp.1577-1589.

Chapman, D.E., Keefe, K.A. \& Wilcox, K.S., 2003. Evidence for functionally distinct synaptic NMDA receptors in ventromedial versus dorsolateral striatum. Journal of neurophysiology, 89(1), pp.69-80.

Chen, H.-S.V. et al., 1998. Neuroprotective concentrations of the N-methyl-D-aspartate openchannel blocker memantine are effective without cytoplasmic vacuolation following post-ischemic administration and do not block maze learning or long-term potentiation. Neuroscience, 86(4), pp.1121-1132.

Chen, M. et al., 2008. Differential roles of NMDA receptor subtypes in ischemic neuronal cell death and ischemic tolerance. Stroke; a journal of cerebral circulation, 39(11), pp.3042-3048.

Chen, N. et al., 1999. Subtype-Specific Enhancement of NMDA Receptor Currents by Mutant Huntingtin. Journal of neurochemistry, 72(5), pp.1890-1898.

Choi, D.W., 1995. Calcium: still center-stage in hypoxic-ischemic neuronal death. Trends in 
NMDA Excitotoxicity Huntington's Disease

neurosciences, 18(2), pp.58-60.

Choi, D.W., Koh, J.Y. \& Peters, S., 1988. Pharmacology of glutamate neurotoxicity in cortical cell culture: attenuation by NMDA antagonists. The Journal of neuroscience: the official journal of the Society for Neuroscience, 8(1), pp.185-196.

Christopherson, K.S. et al., 1999. PSD-95 Assembles a Ternary Complex with the N-MethylD-aspartic Acid Receptor and a Bivalent Neuronal NO Synthase PDZ Domain. The Journal of biological chemistry, 274(39), pp.27467-27473.

Clements, J.D. \& Westbrook, G.L., 1991. Activation kinetics reveal the number of glutamate and glycine binding sites on the N-methyl-d-aspartate receptor. Neuron, 7(4), pp.605613.

Cook, D.J., Teves, L. \& Tymianski, M., 2012a. A translational paradigm for the preclinical evaluation of the stroke neuroprotectant Tat-NR2B9c in gyrencephalic nonhuman primates. Science translational medicine, 4(154), p.154ra133.

Cook, D.J., Teves, L. \& Tymianski, M., 2012b. Treatment of stroke with a PSD-95 inhibitor in the gyrencephalic primate brain. Nature, 483(7388), pp.213-217.

Cottrell, J.R. et al., 2000. Distribution, density, and clustering of functional glutamate receptors before and after synaptogenesis in hippocampal neurons. Journal of neurophysiology, 84(3), pp.1573-1587.

Cowan, C.M. et al., 2008. Polyglutamine-modulated striatal calpain activity in YAC transgenic huntington disease mouse model: impact on NMDA receptor function and toxicity. The Journal of neuroscience: the official journal of the Society for Neuroscience, 28(48), pp.12725-12735.

Coyle, J.T. \& Robert, S., 1976. Lesion of striatal neurons with kainic acid provides a model for Huntington's chorea. Nature, 263(5574), pp.244-246.

Cull-Candy, S. et al., 2001. NMDA receptor subunits: diversity, development and disease. 
NMDA Excitotoxicity Huntington's Disease

Current opinion in neurobiology, 11(3), pp.327-335.

Cull-Candy, S.G. \& Leszkiewicz, D.N., 2004. Role of distinct NMDA receptor subtypes at central synapses. Science's STKE: signal transduction knowledge environment, 2004(255), p.re16.

Danysz, W. \& Parsons, C.G., 2003. The NMDA receptor antagonist memantine as a symptomatological and neuroprotective treatment for Alzheimer's disease: preclinical evidence. International journal of geriatric psychiatry, 18(Suppl 1), pp.S23-32.

Danysz, W., Wojciech, D. \& Parsons, C.G., 2012. Alzheimer's disease, $\beta$-amyloid, glutamate, NMDA receptors and memantine - searching for the connections. British journal of pharmacology, 167(2), pp.324-352.

Dau, A. et al., 2014. Chronic blockade of extrasynaptic NMDA receptors ameliorates synaptic dysfunction and pro-death signaling in Huntington disease transgenic mice. Neurobiology of disease, 62, pp.533-542.

Dawson, V.L. et al., 1991. Nitric oxide mediates glutamate neurotoxicity in primary cortical cultures. Proceedings of the National Academy of Sciences of the United States of America, 88(14), pp.6368-6371.

DeRidder, M.N. et al., 2006. Traumatic mechanical injury to the hippocampus in vitro causes regional caspase- 3 and calpain activation that is influenced by NMDA receptor subunit composition. Neurobiology of disease, 22(1), pp.165-176.

Dérijard, B. et al., 1994. JNK1: a protein kinase stimulated by UV light and Ha-Ras that binds and phosphorylates the c-Jun activation domain. Cell, 76(6), pp.1025-1037.

Dick, O. \& Bading, H., 2010. Synaptic activity and nuclear calcium signaling protect hippocampal neurons from death signal-associated nuclear translocation of FoxO3a induced by extrasynaptic N-methyl-D-aspartate receptors. The Journal of biological chemistry, 285(25), pp.19354-19361. 
NMDA Excitotoxicity Huntington's Disease

Didier, M. et al., 1989. Cerebellar granule cell survival and maturation induced by K and NMDA correlate with c-fos proto-oncogene expression. Neuroscience letters, 107(1-3), pp.55-62.

Dingledine, R. et al., 1999. The glutamate receptor ion channels. Pharmacological reviews, 51(1), pp.7-61.

Doğan, A. et al., 1997. Effects of ifenprodil, a polyamine site NMDA receptor antagonist, on reperfusion injury after transient focal cerebral ischemia. Journal of neurosurgery, 87(6), pp.921-926.

Drejer, J. et al., 1985. Cellular origin of ischemia-induced glutamate release from brain tissue in vivo and in vitro. Journal of neurochemistry, 45(1), pp.145-151.

El-Husseini, A.E. et al., 2000. PSD-95 involvement in maturation of excitatory synapses. Science, 290(5495), pp.1364-1368.

Fan, J. et al., 2009. Interaction of Postsynaptic Density Protein-95 with NMDA Receptors Influences Excitotoxicity in the Yeast Artificial Chromosome Mouse Model of Huntington's Disease. Journal of Neuroscience, 29(35), pp.10928-10938.

Fan, M.M.Y. et al., 2007. Altered NMDA Receptor Trafficking in a Yeast Artificial Chromosome Transgenic Mouse Model of Huntington’s Disease. Journal of Neuroscience, 27(14), pp.3768-3779.

Fan, X. et al., 2014. Rapid and reversible knockdown of endogenous proteins by peptidedirected lysosomal degradation. Nature neuroscience, 17(3), pp.471-480.

Farinelli, M. et al., 2012. Selective regulation of NR2B by protein phosphatase-1 for the control of the NMDA receptor in neuroprotection. PloS one, 7(3), p.e34047.

Fischer, G. et al., 1997. Ro 25-6981, a highly potent and selective blocker of N-methyl-Daspartate receptors containing the NR2B subunit. Characterization in vitro. The Journal of pharmacology and experimental therapeutics, 283(3), pp.1285-1292. 
NMDA Excitotoxicity Huntington's Disease

Flint, A.C. et al., 1997. NR2A subunit expression shortens NMDA receptor synaptic currents in developing neocortex. The Journal of neuroscience: the official journal of the Society for Neuroscience, 17(7), pp.2469-2476.

Foster, K.A. et al., 2010. Distinct roles of NR2A and NR2B cytoplasmic tails in long-term potentiation. The Journal of neuroscience: the official journal of the Society for Neuroscience, 30(7), pp.2676-2685.

Franklin, J.L. \& Johnson, E.M., Jr, 1992. Suppression of programmed neuronal death by sustained elevation of cytoplasmic calcium. Trends in neurosciences, 15(12), pp.501508.

Freedman, J.K. \& Potts, A.M., 1962. Repression of glutaminase I in the rat retina by administration of sodium-L-glutamate. Investigative ophthalmology, 1, pp.118-121.

Friedman, L.K., 2006. Calcium: a role for neuroprotection and sustained adaptation. Molecular interventions, 6(6), pp.315-329.

Gafni, J. \& Ellerby, L.M., 2002. Calpain activation in Huntington's disease. The Journal of neuroscience: the official journal of the Society for Neuroscience, 22(12), pp.48424849.

Garcia-Bonilla, L. et al., 2006. Calpain-induced proteolysis after transient global cerebral ischemia and ischemic tolerance in a rat model. Neurochemical research, 31(12), pp.1433-1441.

Gascón, S. et al., 2008. Excitotoxicity and focal cerebral ischemia induce truncation of the NR2A and NR2B subunits of the NMDA receptor and cleavage of the scaffolding protein PSD-95. Molecular psychiatry, 13(1), pp.99-114.

Gladding, C.M. et al., 2012. Calpain and Striatal-Enriched protein tyrosine phosphatase (STEP) activation contribute to extrasynaptic NMDA receptor localization in a Huntington's disease mouse model. Human molecular genetics, 21(17), pp.3739-3752. 
NMDA Excitotoxicity Huntington's Disease

Gladding, C.M. \& Raymond, L.A., 2011. Mechanisms underlying NMDA receptor synaptic/extrasynaptic distribution and function. Molecular and cellular neurosciences, 48(4), pp.308-320.

Gogas, K.R., 2006. Glutamate-based therapeutic approaches: NR2B receptor antagonists. Current opinion in pharmacology, 6(1), pp.68-74.

Gong, Y. et al., 2006. Sterol-regulated ubiquitination and degradation of Insig-1 creates a convergent mechanism for feedback control of cholesterol synthesis and uptake. Cell metabolism, 3(1), pp.15-24.

Görgülü, A. et al., 2000. Reduction of edema and infarction by Memantine and MK-801 after focal cerebral ischaemia and reperfusion in rat. Acta neurochirurgica, 142(11), pp.12871292.

Gotti, B. et al., 1988. Ifenprodil and SL 82.0715 as cerebral anti-ischemic agents. I. Evidence for efficacy in models of focal cerebral ischemia. The Journal of pharmacology and experimental therapeutics, 247(3), pp.1211-1221.

Gouix, E. et al., 2009. Reverse glial glutamate uptake triggers neuronal cell death through extrasynaptic NMDA receptor activation. Molecular and cellular neurosciences, 40(4), pp.463-473.

Graham, D., Darles, G. \& Langer, S.Z., 1992. The neuroprotective properties of ifenprodil, a novel NMDA receptor antagonist, in neuronal cell culture toxicity studies. European journal of pharmacology, 226(4), pp.373-376.

Graham, R.K. et al., 2009. Differential Susceptibility to Excitotoxic Stress in YAC128 Mouse Models of Huntington Disease between Initiation and Progression of Disease. Journal of Neuroscience, 29(7), pp.2193-2204.

Graveland GA, Williams RS, Difiglia M. Evidence for degenerative and regenerative changes in neostriatal spiny neurons in Huntington's disease. Science. 
NMDA Excitotoxicity Huntington's Disease

$1985 ; 227(4688): 770-3$.

Groc, L. et al., 2006. NMDA receptor surface mobility depends on NR2A-2B subunits. Proceedings of the National Academy of Sciences of the United States of America, 103(49), pp.18769-18774.

Grotta, J.C. et al., 1990. CGS-19755, a competitive NMDA receptor antagonist, reduces calcium-calmodulin binding and improves outcome after global cerebral ischemia. Annals of neurology, 27(6), pp.612-619.

Guttmann, R.P. et al., 2002. Proteolysis of the N-methyl-d-aspartate receptor by calpain in situ. The Journal of pharmacology and experimental therapeutics, 302(3), pp.10231030.

Guttmann, R.P. et al., 2001. Specific proteolysis of the NR2 subunit at multiple sites by calpain. Journal of neurochemistry, 78(5), pp.1083-1093.

Haddad, J.J., 2005. N-methyl-D-aspartate (NMDA) and the regulation of mitogen-activated protein kinase (MAPK) signaling pathways: a revolving neurochemical axis for therapeutic intervention? Progress in neurobiology, 77(4), pp.252-282.

Hansson, O. et al., 2001. Resistance to NMDA toxicity correlates with appearance of nuclear inclusions, behavioural deficits and changes in calcium homeostasis in mice transgenic for exon 1 of the huntington gene. The European journal of neuroscience, 14(9), pp.1492-1504.

Hardingham, G.E. \& Bading, H., 2010. Synaptic versus extrasynaptic NMDA receptor signalling: implications for neurodegenerative disorders. Nature reviews. Neuroscience, 11(10), pp.682-696.

Hardingham, G.E. \& Bading, H., 2003. The Yin and Yang of NMDA receptor signalling. Trends in neurosciences, 26(2), pp.81-89.

Hardingham, G.E., Fukunaga, Y. \& Bading, H., 2002. Extrasynaptic NMDARs oppose 
NMDA Excitotoxicity Huntington's Disease

synaptic NMDARs by triggering CREB shut-off and cell death pathways. Nature neuroscience, 5(5), pp.405-414.

Harjes, P. \& Wanker, E.E., 2003. The hunt for huntingtin function: interaction partners tell many different stories. Trends in biochemical sciences, 28(8), pp.425-433.

Harper, S.J. \& Wilkie, N., 2003. MAPKs: new targets for neurodegeneration. Expert opinion on therapeutic targets, 7(2), pp.187-200.

Harris, A.Z. \& Pettit, D.L., 2007. Extrasynaptic and synaptic NMDA receptors form stable and uniform pools in rat hippocampal slices. The Journal of physiology, 584(Pt 2), pp.509-519.

Harris, M.E. et al., 1996. Amyloid beta peptide (25-35) inhibits Na+-dependent glutamate uptake in rat hippocampal astrocyte cultures. Journal of neurochemistry, 67(1), pp.277286.

Henshall, D.C. et al., 2003. Expression of death-associated protein kinase and recruitment to the tumor necrosis factor signaling pathway following brief seizures. Journal of neurochemistry, 86(5), pp.1260-1270.

Hill, M.D. et al., 2012. Safety and efficacy of NA-1 in patients with iatrogenic stroke after endovascular aneurysm repair (ENACT): a phase 2, randomised, double-blind, placebocontrolled trial. Lancet neurology, 11(11), pp.942-950.

Hodgson, J.G. et al., 1999. A YAC mouse model for Huntington's disease with full-length mutant huntingtin, cytoplasmic toxicity, and selective striatal neurodegeneration. Neuron, 23(1), pp.181-192.

Howard, R. et al., 2012. Donepezil and memantine for moderate-to-severe Alzheimer's disease. The New England journal of medicine, 366(10), pp.893-903.

Huang, H., 1996. Interactions between Ifenprodil and the NR2B Subunit of the N-Methyl-Daspartate Receptor. The Journal of biological chemistry, 271(16), pp.9603-9611. 
NMDA Excitotoxicity Huntington's Disease

Huang, K. et al., 2004. Huntingtin-Interacting Protein HIP14 Is a Palmitoyl Transferase Involved in Palmitoylation and Trafficking of Multiple Neuronal Proteins. Neuron, 44(6), pp.977-986.

Hu, N.-W. et al., 2009. GluN2B subunit-containing NMDA receptor antagonists prevent Abeta-mediated synaptic plasticity disruption in vivo. Proceedings of the National Academy of Sciences of the United States of America, 106(48), pp.20504-20509.

Ikonomidou, C. \& Turski, L., 2002. Why did NMDA receptor antagonists fail clinical trials for stroke and traumatic brain injury? Lancet neurology, 1(6), pp.383-386.

Ishii, T. et al., 1993. Molecular characterization of the family of the N-methyl-D-aspartate receptor subunits. The Journal of biological chemistry, 268(4), pp.2836-2843.

Izumi, Y., Tokuda, K. \& Zorumski, C.F., 2008. Long-term potentiation inhibition by lowlevel N-methyl-D-aspartate receptor activation involves calcineurin, nitric oxide, and p38 mitogen-activated protein kinase. Hippocampus, 18(3), pp.258-265.

Jarabek, B.R., 2003. Regulation of proteins affecting NMDA receptor-induced excitotoxicity in a Huntington's mouse model. Brain: a journal of neurology, 127(3), pp.505-516.

Johnson, J.W. \& Ascher, P., 1987. Glycine potentiates the NMDA response in cultured mouse brain neurons. Nature, 325(6104), pp.529-531.

Jurado, S. et al., 2010. PTEN is recruited to the postsynaptic terminal for NMDA receptordependent long-term depression. The EMBO journal, 29(16), pp.2827-2840.

Kaltenbach, L.S. et al., 2007. Huntingtin interacting proteins are genetic modifiers of neurodegeneration. PLoS genetics, 3(5), p.e82.

Kandel, E.R., Schwartz, J.H. \& Jessell, T.M., 1995. Essentials of Neural Science and Behavior, McGraw Hill Professional.

Katagiri, H., Tanaka, K. \& Manabe, T., 2001. Requirement of appropriate glutamate concentrations in the synaptic cleft for hippocampal LTP induction. The European 
NMDA Excitotoxicity Huntington's Disease

journal of neuroscience, 14(3), pp.547-553.

Katsura, K.-I. et al., 1992. Coupling among changes in energy metabolism, acid-base homeostasis, and ion fluxes in ischemia. Canadian journal of physiology and pharmacology, 70(S1), pp.S170-S175.

Kew, J.N., Trube, G. \& Kemp, J.A., 1996. A novel mechanism of activity-dependent NMDA receptor antagonism describes the effect of ifenprodil in rat cultured cortical neurones. The Journal of physiology, 497 ( Pt 3), pp.761-772.

Kim, M.J. et al., 2005. Differential roles of NR2A- and NR2B-containing NMDA receptors in Ras-ERK signaling and AMPA receptor trafficking. Neuron, 46(5), pp.745-760.

Klapstein, G.J. et al., 2001. Electrophysiological and morphological changes in striatal spiny neurons in R6/2 Huntington's disease transgenic mice. Journal of neurophysiology, 86(6), pp.2667-2677.

Klyubin, I. et al., 2011. Protection against A $\beta$-mediated rapid disruption of synaptic plasticity and memory by memantine. Neurobiology of aging, 32(4), pp.614-623.

Koga, H. et al., 2011. A photoconvertible fluorescent reporter to track chaperone-mediated autophagy. Nature communications, 2, p.386.

Koike, T., Martin, D.P. \& Johnson, E.M., Jr, 1989. Role of Ca2+ channels in the ability of membrane depolarization to prevent neuronal death induced by trophic-factor deprivation: evidence that levels of internal $\mathrm{Ca} 2+$ determine nerve growth factor dependence of sympathetic ganglion cells. Proceedings of the National Academy of Sciences of the United States of America, 86(16), pp.6421-6425.

Kornau, H.C. et al., 1995. Domain interaction between NMDA receptor subunits and the postsynaptic density protein PSD-95. Science, 269(5231), pp.1737-1740.

Krapivinsky, G. et al., 2003. The NMDA Receptor Is Coupled to the ERK Pathway by a Direct Interaction between NR2B and RasGRF1. Neuron, 40(4), pp.775-784. 
NMDA Excitotoxicity Huntington's Disease

Kremer, B., Clark, C., Almqvist, E., Raymond, L., Graf, P., Jacova, C., Mezei, M., Hardy, M., Snow, B., Martin, W. and Hayden, M. (1999). Influence of lamotrigine on progression of early Huntington disease: A randomized clinical trial. Neurology, 53(5), pp.1000-1000.

Kutsuwada, T. et al., 1992. Molecular diversity of the NMDA receptor channel. Nature, 358(6381), pp.36-41.

Lai, T.W., Shu, Z. \& Wang, Y.T., 2014. Excitotoxicity and stroke: Identifying novel targets for neuroprotection. Progress in neurobiology, 115, pp.157-188.

Lai, T.W., Shyu, W.-C. \& Wang, Y.T., 2011. Stroke intervention pathways: NMDA receptors and beyond. Trends in molecular medicine, 17(5), pp.266-275.

Lai, T.W. \& Wang, Y.T., 2010. Fashioning drugs for stroke. Nature medicine, 16(12), pp.1376-1378.

Lan, J.Y. et al., 2001. Protein kinase C modulates NMDA receptor trafficking and gating. Nature neuroscience, 4(4), pp.382-390.

Lapchak, P.A., 2006. Memantine, an uncompetitive low affinity NMDA open-channel antagonist improves clinical rating scores in a multiple infarct embolic stroke model in rabbits. Brain research, 1088(1), pp.141-147.

Lee, H.K. et al., 1998. NMDA induces long-term synaptic depression and dephosphorylation of the GluR1 subunit of AMPA receptors in hippocampus. Neuron, 21(5), pp.11511162.

Lee, K.S. et al., 1991. Inhibition of proteolysis protects hippocampal neurons from ischemia. Proceedings of the National Academy of Sciences of the United States of America, 88(16), pp.7233-7237.

Lee, M.S. et al., 2000. Neurotoxicity induces cleavage of p35 to p25 by calpain. Nature, 405(6784), pp.360-364. 
NMDA Excitotoxicity Huntington's Disease

Lester, R.A.J. et al., 1990. Channel kinetics determine the time course of NMDA receptormediated synaptic currents. Nature, 346(6284), pp.565-567.

Liang, Z. et al., 2008. Decrease of protein phosphatase 2A and its association with accumulation and hyperphosphorylation of tau in Down syndrome. Journal of Alzheimer's disease: JAD, 13(3), pp.295-302.

Li, D.M. \& Sun, H., 1998. PTEN/MMAC1/TEP1 suppresses the tumorigenicity and induces G1 cell cycle arrest in human glioblastoma cells. Proceedings of the National Academy of Sciences of the United States of America, 95(26), pp.15406-15411.

Li, J.H. et al., 1998. Developmental changes in localization of NMDA receptor subunits in primary cultures of cortical neurons. The European journal of neuroscience, 10(5), pp.1704-1715.

Lipton, S.A., 2004a. Failures and successes of NMDA receptor antagonists: molecular basis for the use of open-channel blockers like memantine in the treatment of acute and chronic neurologic insults. NeuroRx: the journal of the American Society for Experimental NeuroTherapeutics, 1(1), pp.101-110.

Lipton, S.A., 2004b. Paradigm shift in NMDA receptor antagonist drug development: molecular mechanism of uncompetitive inhibition by memantine in the treatment of Alzheimer's disease and other neurologic disorders. Journal of Alzheimer's disease: $J A D, 6(6$ Suppl), pp.S61-74.

Li, S. et al., 2011. Soluble A $\beta$ oligomers inhibit long-term potentiation through a mechanism involving excessive activation of extrasynaptic NR2B-containing NMDA receptors. The Journal of neuroscience: the official journal of the Society for Neuroscience, 31(18), pp.6627-6638.

Li, S. et al., 2009. Soluble Oligomers of Amyloid $\beta$ Protein Facilitate Hippocampal LongTerm Depression by Disrupting Neuronal Glutamate Uptake. Neuron, 62(6), pp.788- 
NMDA Excitotoxicity Huntington's Disease

801.

Liu, D.-D. et al., 2013. Activation of extrasynaptic NMDA receptors induces LTD in rat hippocampal CA1 neurons. Brain research bulletin, 93, pp.10-16.

Liu, L., 2004. Role of NMDA Receptor Subtypes in Governing the Direction of Hippocampal Synaptic Plasticity. Science, 304(5673), pp.1021-1024.

Liu, Y. et al., 2007. NMDA receptor subunits have differential roles in mediating excitotoxic neuronal death both in vitro and in vivo. The Journal of neuroscience: the official journal of the Society for Neuroscience, 27(11), pp.2846-2857.

Li, X. et al., 2009. Mutant huntingtin impairs vesicle formation from recycling endosomes by interfering with Rab11 activity. Molecular and cellular biology, 29(22), pp.6106-6116.

López-Menéndez, C. et al., 2009. Kidins220/ARMS downregulation by excitotoxic activation of NMDARs reveals its involvement in neuronal survival and death pathways. Journal of cell science, 122(Pt 19), pp.3554-3565.

Löschmann, P.-A. et al., 2004. Antiparkinsonian activity of Ro 25-6981, a NR2B subunit specific NMDA receptor antagonist, in animal models of Parkinson's disease. Experimental neurology, 187(1), pp.86-93.

Lucas, D.R. \& Newhouse, J.P., 1957. The toxic effect of sodium L-glutamate on the inner layers of the retina. A.M.A. archives of ophthalmology, 58(2), pp.193-201.

Lu, W. et al., 2001. Activation of synaptic NMDA receptors induces membrane insertion of new AMPA receptors and LTP in cultured hippocampal neurons. Neuron, 29(1), pp.243254.

MacDermott, A.B. et al., 1986. NMDA-receptor activation increases cytoplasmic calcium concentration in cultured spinal cord neurones. Nature, 321(6069), pp.519-522.

MacDonald, M.E. et al., 1993. A novel gene containing a trinucleotide repeat that is expanded and unstable on Huntington's disease chromosomes. Cell, 72(6), pp.971-983. 
NMDA Excitotoxicity Huntington's Disease

Macdonald, M. \& M, M., 1993. A novel gene containing a trinucleotide repeat that is expanded and unstable on Huntington's disease chromosomes. Cell, 72(6), pp.971-983.

Man, H.-Y. et al., 2003. Activation of PI3-kinase is required for AMPA receptor insertion during LTP of mEPSCs in cultured hippocampal neurons. Neuron, 38(4), pp.611-624.

Martel, M.-A. et al., 2012. The Subtype of GluN2 C-terminal Domain Determines the Response to Excitotoxic Insults. Neuron, 74(3), pp.543-556.

Martel, M.-A., Wyllie, D.J.A. \& Hardingham, G.E., 2009. In developing hippocampal neurons, NR2B-containing N-methyl-D-aspartate receptors (NMDARs) can mediate signaling to neuronal survival and synaptic potentiation, as well as neuronal death. Neuroscience, 158(1), pp.334-343.

Martin, H.G.S. \& Wang, Y.T., 2010. Blocking the deadly effects of the NMDA receptor in stroke. Cell, 140(2), pp.174-176.

Marvanová, M. et al., 2001. The Neuroprotective Agent Memantine Induces Brain-Derived Neurotrophic Factor and trkB Receptor Expression in Rat Brain. Molecular and cellular neurosciences, 18(3), pp.247-258.

Matsumoto, T. et al., 1990. Cortical activity, ionic homeostasis, and acidosis during rat brain repetitive ischemia. Stroke; a journal of cerebral circulation, 21(8), pp.1192-1198.

Mayer, M.L., Westbrook, G.L. \& Guthrie, P.B., 1984. Voltage-dependent block by Mg2 of NMDA responses in spinal cord neurones. Nature, 309(5965), pp.261-263.

Meguro, H. et al., 1992. Functional characterization of a heteromeric NMDA receptor channel expressed from cloned cDNAs. Nature, 357(6373), pp.70-74.

Merchant, R.E. et al., 1999. A Double-Blind, Placebo-Controlled Study of the Safety, Tolerability and Pharmacokinetics of CP-101,606 in Patients with a Mild or Moderate Traumatic Brain Injury. Annals of the New York Academy of Sciences, 890(1 NEUROPROTECTI), pp.42-50. 
NMDA Excitotoxicity Huntington's Disease

Milnerwood, A.J. et al., 2006. Early development of aberrant synaptic plasticity in a mouse model of Huntington's disease. Human molecular genetics, 15(10), pp.1690-1703.

Milnerwood, A.J. et al., 2010. Early Increase in Extrasynaptic NMDA Receptor Signaling and Expression Contributes to Phenotype Onset in Huntington's Disease Mice. Neuron, 65(2), pp.178-190.

Milnerwood, A.J. \& Raymond, L.A., 2007. Corticostriatal synaptic function in mouse models of Huntington's disease: early effects of huntingtin repeat length and protein load. The Journal of physiology, 585(3), pp.817-831.

Minnerup, J. et al., 2012. Neuroprotection for stroke: current status and future perspectives. International journal of molecular sciences, 13(9), pp.11753-11772.

Montastruc, J.L. et al., 1992. A pilot study of N-methyl-D-aspartate (NMDA) antagonist in Parkinson's disease. Journal of neurology, neurosurgery, and psychiatry, 55(7), pp.630631.

Monyer, H. et al., 1992. Heteromeric NMDA Receptors: Molecular and Functional Distinction of Subtypes. Science, 256(5060), pp.1217-1221.

Mori, H. \& Mishina, M., 1996. [Molecular diversity and physiological roles of the NMDAreceptor channel]. Nihon yakurigaku zasshi. Folia pharmacologica Japonica, 108(1), pp.1-12.

Moriyoshi, K. et al., 1991. Molecular cloning and characterization of the rat NMDA receptor. Nature, 354(6348), pp.31-37.

Mukherjee, D. \& Patil, C.G., 2011. Epidemiology and the global burden of stroke. World neurosurgery, 76(6 Suppl), pp.S85-90.

Murphy, K.P. et al., 2000. Abnormal synaptic plasticity and impaired spatial cognition in mice transgenic for exon 1 of the human Huntington's disease mutation. The Journal of neuroscience: the official journal of the Society for Neuroscience, 20(13), pp.5115- 
NMDA Excitotoxicity Huntington's Disease

5123.

Nash, J.E. et al., 2000. Antiparkinsonian actions of ifenprodil in the MPTP-lesioned marmoset model of Parkinson's disease. Experimental neurology, 165(1), pp.136-142.

Nash, J.E. et al., 2004. The NR2B-selective NMDA receptor antagonist CP-101,606 exacerbates L-DOPA-induced dyskinesia and provides mild potentiation of antiparkinsonian effects of L-DOPA in the MPTP-lesioned marmoset model of Parkinson's disease. Experimental neurology, 188(2), pp.471-479.

Nash, J.E., Hill, M.P. \& Brotchie, J.M., 1999. Antiparkinsonian actions of blockade of NR2B-containing NMDA receptors in the reserpine-treated rat. Experimental neurology, 155(1), pp.42-48.

Ning, K. et al., 2004. Dual neuroprotective signaling mediated by downregulating two distinct phosphatase activities of PTEN. The Journal of neuroscience: the official journal of the Society for Neuroscience, 24(16), pp.4052-4060.

Nishikawa, T. et al., 1994. NPC17742, a Competitive NMDA Receptor Antagonist, Reduces Brain Injury after Transient Focal Ischemia in Cats. Anesthesiology, 81(SUPPLEMENT), p.A850.

O’Donnell, L.A. et al., 2006. Human immunodeficiency virus (HIV)-induced neurotoxicity: roles for the NMDA receptor subtypes. The Journal of neuroscience: the official journal of the Society for Neuroscience, 26(3), pp.981-990.

Okamoto, S.-I. et al., 2009. Balance between synaptic versus extrasynaptic NMDA receptor activity influences inclusions and neurotoxicity of mutant huntingtin. Nature medicine, 15(12), pp.1407-1413.

Olney, J.W. \& Sharpe, L.G., 1969. Brain Lesions in an Infant Rhesus Monkey Treated with Monosodium Glutamate. Science, 166(3903), pp.386-388.

Papadia, S. et al., 2005. Nuclear Ca2+ and the cAMP response element-binding protein 
NMDA Excitotoxicity Huntington's Disease

family mediate a late phase of activity-dependent neuroprotection. The Journal of neuroscience: the official journal of the Society for Neuroscience, 25(17), pp.42794287.

Papouin, T. et al., 2012. Synaptic and Extrasynaptic NMDA Receptors Are Gated by Different Endogenous Coagonists. Cell, 150(3), pp.633-646.

Parsons, M.P. \& Raymond, L.A., 2014. Extrasynaptic NMDA receptor involvement in central nervous system disorders. Neuron, 82(2), pp.279-293.

Parsons M.P. et al., 2016 Real-time imaging of glutamate clearance reveals normal striatal uptake in Huntington disease mouse models. Nat Commun, 7, pp. 11251.

Patrick, G.N. et al., 1999. Conversion of p35 to p25 deregulates Cdk5 activity and promotes neurodegeneration. Nature, 402(6762), pp.615-622.

Paul, S. et al., 2002. NMDA-mediated activation of the tyrosine phosphatase STEP regulates the duration of ERK signaling. Nature neuroscience, 6(1), pp.34-42.

Petralia, R.S. et al., 2010. Organization of NMDA receptors at extrasynaptic locations. Neuroscience, 167(1), pp.68-87.

Rami, A. \& Krieglstein, J., 1993. Protective effects of calpain inhibitors against neuronal damage caused by cytotoxic hypoxia in vitro and ischemia in vivo. Brain research, 609(1-2), pp.67-70.

Reisberg, B. et al., 1989. The stage specific temporal course of Alzheimer's disease: functional and behavioral concomitants based upon cross-sectional and longitudinal observation. Progress in clinical and biological research, 317, pp.23-41.

Rosenmund, C., Clements, J. \& Westbrook, G., 1993. Nonuniform probability of glutamate release at a hippocampal synapse. Science, 262(5134), pp.754-757.

Rothman, S., 1983. Synaptic activity mediates death of hypoxic neurons. Science, 220(4596), pp.536-537. 
NMDA Excitotoxicity Huntington's Disease

Rothman, S., 1984. Synaptic release of excitatory amino acid neurotransmitter mediates anoxic neuronal death. The Journal of neuroscience: the official journal of the Society for Neuroscience, 4(7), pp.1884-1891.

Sanz-Clemente, A., Nicoll, R.A. \& Roche, K.W., 2013. Diversity in NMDA receptor composition: many regulators, many consequences. The Neuroscientist: a review journal bringing neurobiology, neurology and psychiatry, 19(1), pp.62-75.

Sattler, R. et al., 1999. Specific coupling of NMDA receptor activation to nitric oxide neurotoxicity by PSD-95 protein. Science, 284(5421), pp.1845-1848.

Shamloo, M. et al., 2005. Death-associated protein kinase is activated by dephosphorylation in response to cerebral ischemia. The Journal of biological chemistry, 280(51), pp.42290-42299.

Shehadeh, J. et al., 2006. Striatal neuronal apoptosis is preferentially enhanced by NMDA receptor activation in YAC transgenic mouse model of Huntington disease. Neurobiology of disease, 21(2), pp.392-403.

Sheng, M. et al., 1994. Changing subunit composition of heteromeric NMDA receptors during development of rat cortex. Nature, 368(6467), pp.144-147.

Shibasaki, F. \& McKeon, F., 1995. Calcineurin functions in $\mathrm{Ca}(2+)$-activated cell death in mammalian cells. The Journal of cell biology, 131(3), pp.735-743.

Shohat, G. et al., 2001. The pro-apoptotic function of death-associated protein kinase is controlled by a unique inhibitory autophosphorylation-based mechanism. The Journal of biological chemistry, 276(50), pp.47460-47467.

Siman, R. \& Carl Noszek, J., 1988. Excitatory amino acids activate calpain I and induce structural protein breakdown in vivo. Neuron, 1(4), pp.279-287.

Simon, R.P. et al., 1984. Blockade of N-methyl-D-aspartate receptors may protect against ischemic damage in the brain. Science, 226(4676), pp.850-852. 
NMDA Excitotoxicity Huntington's Disease

Singaraja, R.R. et al., 2002. HIP14, a novel ankyrin domain-containing protein, links huntingtin to intracellular trafficking and endocytosis. Human molecular genetics, 11(23), pp.2815-2828.

Snyder, E.M. et al., 2005. Regulation of NMDA receptor trafficking by amyloid- $\beta$. Nature neuroscience, 8(8), pp.1051-1058.

Song, M.S. et al., 2008. Memantine protects rat cortical cultured neurons against betaamyloid-induced toxicity by attenuating tau phosphorylation. The European journal of neuroscience, 28(10), pp.1989-2002.

Soriano, F.X. et al., 2008. Specific targeting of pro-death NMDA receptor signals with differing reliance on the NR2B PDZ ligand. The Journal of neuroscience: the official journal of the Society for Neuroscience, 28(42), pp.10696-10710.

Spargo, E., Everall, I.P. \& Lantos, P.L., 1993. Neuronal loss in the hippocampus in Huntington's disease: a comparison with HIV infection. Journal of neurology, neurosurgery, and psychiatry, 56(5), pp.487-491.

Sprengel, R. et al., 1998. Importance of the intracellular domain of NR2 subunits for NMDA receptor function in vivo. Cell, 92(2), pp.279-289.

Sun, Y. et al., 2001. Polyglutamine-expanded huntingtin promotes sensitization of N-methylD-aspartate receptors via post-synaptic density 95. The Journal of biological chemistry, 276(27), pp.24713-24718.

Sun, Z. et al., 2002. Differential Changes in Striatal Projection Neurons in R6/2 Transgenic Mice for Huntington's Disease. Neurobiology of disease, 11(3), pp.369-385.

Szydlowska, K., Kinga, S. \& Michael, T., 2010. Calcium, ischemia and excitotoxicity. Cell calcium, 47(2), pp.122-129.

Taghibiglou, C. et al., 2009. Role of NMDA receptor-dependent activation of SREBP1 in excitotoxic and ischemic neuronal injuries. Nature medicine, 15(12), pp.1399-1406. 
NMDA Excitotoxicity Huntington's Disease

Tang, T.-S. et al., 2005. Disturbed Ca2 signaling and apoptosis of medium spiny neurons in Huntington's disease. Proceedings of the National Academy of Sciences, 102(7), pp.2602-2607.

Terasaki, Y. et al., 2010. Activation of NR2A receptors induces ischemic tolerance through CREB signaling. Journal of cerebral blood flow and metabolism: official journal of the International Society of Cerebral Blood Flow and Metabolism, 30(8), pp.1441-1449.

Thomas, C.G., 2006. Synaptic and Extrasynaptic NMDA Receptor NR2 Subunits in Cultured Hippocampal Neurons. Journal of neurophysiology, 95(3), pp.1727-1734.

Tovar, K.R., McGinley, M.J. \& Westbrook, G.L., 2013. Triheteromeric NMDA Receptors at Hippocampal Synapses. Journal of Neuroscience, 33(21), pp.9150-9160.

Tovar, K.R. \& Westbrook, G.L., 1999. The incorporation of NMDA receptors with a distinct subunit composition at nascent hippocampal synapses in vitro. The Journal of neuroscience: the official journal of the Society for Neuroscience, 19(10), pp.41804188.

Trotman, L.C. et al., 2007. Ubiquitination regulates PTEN nuclear import and tumor suppression. Cell, 128(1), pp.141-156.

Turski, L. et al., 1991. Protection of substantia nigra from MPP neurotoxicity by N-methylD-aspartate antagonists. Nature, 349(6308), pp.414-418.

Tu, W. et al., 2010. DAPK1 interaction with NMDA receptor NR2B subunits mediates brain damage in stroke. Cell, 140(2), pp.222-234.

Tymianski, M. et al., 1993. Secondary Ca2+ overload indicates early neuronal injury which precedes staining with viability indicators. Brain research, 607(1-2), pp.319-323.

Tymianski M. Stroke in 2013: disappointments and advances in acute stroke intervention. Nat Rev Neurol. 2014;10(2):66-8.

Usdin, M.T. et al., 1999. Impaired Synaptic Plasticity in Mice Carrying the Huntington's 
NMDA Excitotoxicity Huntington's Disease

Disease Mutation. Human molecular genetics, 8(5), pp.839-846.

Van Harreveld, A., 1959. Compounds in brain extracts causing spreading depression of cerebral cortical activity and contraction of crustacean muscle. Journal of neurochemistry, 3(4), pp.300-315.

Van Raamsdonk, J.M., 2005. Cognitive Dysfunction Precedes Neuropathology and Motor Abnormalities in the YAC128 Mouse Model of Huntington's Disease. Journal of Neuroscience, 25(16), pp.4169-4180.

Vonsattel, J.-P. et al., 1985. Neuropathological Classification of Huntington’s Disease. Journal of neuropathology and experimental neurology, 44(6), pp.559-577.

Wang, C.X. \& Shuaib, A., 2005. NMDA/NR2B selective antagonists in the treatment of ischemic brain injury. Current drug targets. CNS and neurological disorders, 4(2), pp.143-151.

Wang, J.Q. et al., 2004. Glutamate signaling to Ras-MAPK in striatal neurons: mechanisms for inducible gene expression and plasticity. Molecular neurobiology, 29(1), pp.1-14.

Wang, J.Q., Fibuch, E.E. \& Limin, M., 2007. Regulation of mitogen-activated protein kinases by glutamate receptors. Journal of neurochemistry, 100(1), pp.1-11.

Wang, K.K. \& Yuen, P.W., 1994. Calpain inhibition: an overview of its therapeutic potential. Trends in pharmacological sciences, 15(11), pp.412-419.

Wang, Y. et al., 2013. Distinct roles for $\mu$-calpain and m-calpain in synaptic NMDARmediated neuroprotection and extrasynaptic NMDAR-mediated neurodegeneration. The Journal of neuroscience: the official journal of the Society for Neuroscience, 33(48), pp.18880-18892.

Watanabe, M. et al., 1992. Developmental changes in distribution of NMDA receptor channel subunit mRNAs. Neuroreport, 3(12), pp.1138-1140.

Watkins, J.C. \& Evans, R.H., 1981. Excitatory Amino Acid Transmitters. Annual review of 
NMDA Excitotoxicity Huntington's Disease

pharmacology and toxicology, 21(1), pp.165-204.

Wen, Y. et al., 2007. Cdk5 is involved in NFT-like tauopathy induced by transient cerebral ischemia in female rats. Biochimica et biophysica acta, 1772(4), pp.473-483.

Williams, K., 1993. Ifenprodil discriminates subtypes of the N-methyl-D-aspartate receptor: selectivity and mechanisms at recombinant heteromeric receptors. Molecular pharmacology, 44(4), pp.851-859.

Wroge, C.M. et al., 2012. Synaptic NMDA receptors mediate hypoxic excitotoxic death. The Journal of neuroscience: the official journal of the Society for Neuroscience, 32(19), pp.6732-6742.

Xia, P. et al., 2010. Memantine preferentially blocks extrasynaptic over synaptic NMDA receptor currents in hippocampal autapses. The Journal of neuroscience: the official journal of the Society for Neuroscience, 30(33), pp.11246-11250.

Xu, J. et al., 2009. Extrasynaptic NMDA receptors couple preferentially to excitotoxicity via calpain-mediated cleavage of STEP. The Journal of neuroscience: the official journal of the Society for Neuroscience, 29(29), pp.9330-9343.

Yamazaki, M. et al., 1992. Cloning, expression and modulation of a mouse NMDA receptor subunit. FEBS letters, 300(1), pp.39-45.

Yan, G.-M. et al., 1994. Depolarization or glutamate receptor activation blocks apoptotic cell death of cultured cerebellar granule neurons. Brain research, 656(1), pp.43-51.

Young AB, Greenamyre JT, Hollingsworth Z, et al. NMDA receptor losses in putamen from patients with Huntington's disease. Science. 1988;241(4868):981-3.

Yuan, H. et al., 2015. Context-dependent GluN2B-selective inhibitors of NMDA receptor function are neuroprotective with minimal side effects. Neuron, 85(6), pp.1305-1318.

Zeron, M.M. et al., 2002. Increased Sensitivity to N-Methyl-D-Aspartate Receptor-Mediated Excitotoxicity in a Mouse Model of Huntington's Disease. Neuron, 33(6), pp.849-860. 
NMDA Excitotoxicity Huntington's Disease

Zhang, Q.-G. et al., 2007. Critical role of PTEN in the coupling between PI3K/Akt and JNK1/2 signaling in ischemic brain injury. FEBS letters, 581(3), pp.495-505.

Zhang, S. et al., 2013. Critical role of increased PTEN nuclear translocation in excitotoxic and ischemic neuronal injuries. The Journal of neuroscience: the official journal of the Society for Neuroscience, 33(18), pp.7997-8008.

Zhang, S.-J. et al., 2007. Decoding NMDA receptor signaling: identification of genomic programs specifying neuronal survival and death. Neuron, 53(4), pp.549-562.

Zhou, L. et al., 2010. Treatment of cerebral ischemia by disrupting ischemia-induced interaction of nNOS with PSD-95. Nature medicine, 16(12), pp.1439-1443.

Zhou, M. \& Baudry, M., 2006. Developmental changes in NMDA neurotoxicity reflect developmental changes in subunit composition of NMDA receptors. The Journal of neuroscience: the official journal of the Society for Neuroscience, 26(11), pp.29562963.

Zhou, X. et al., 2013. Involvement of the GluN2A and GluN2B subunits in synaptic and extrasynaptic N-methyl-D-aspartate receptor function and neuronal excitotoxicity. The Journal of biological chemistry, 288(33), pp.24151-24159.

Zuccato, C., Valenza, M. \& Cattaneo, E., 2010. Molecular mechanisms and potential therapeutical targets in Huntington's disease. Physiological reviews. Available at: http://physrev.physiology.org/content/90/3/905.short. 


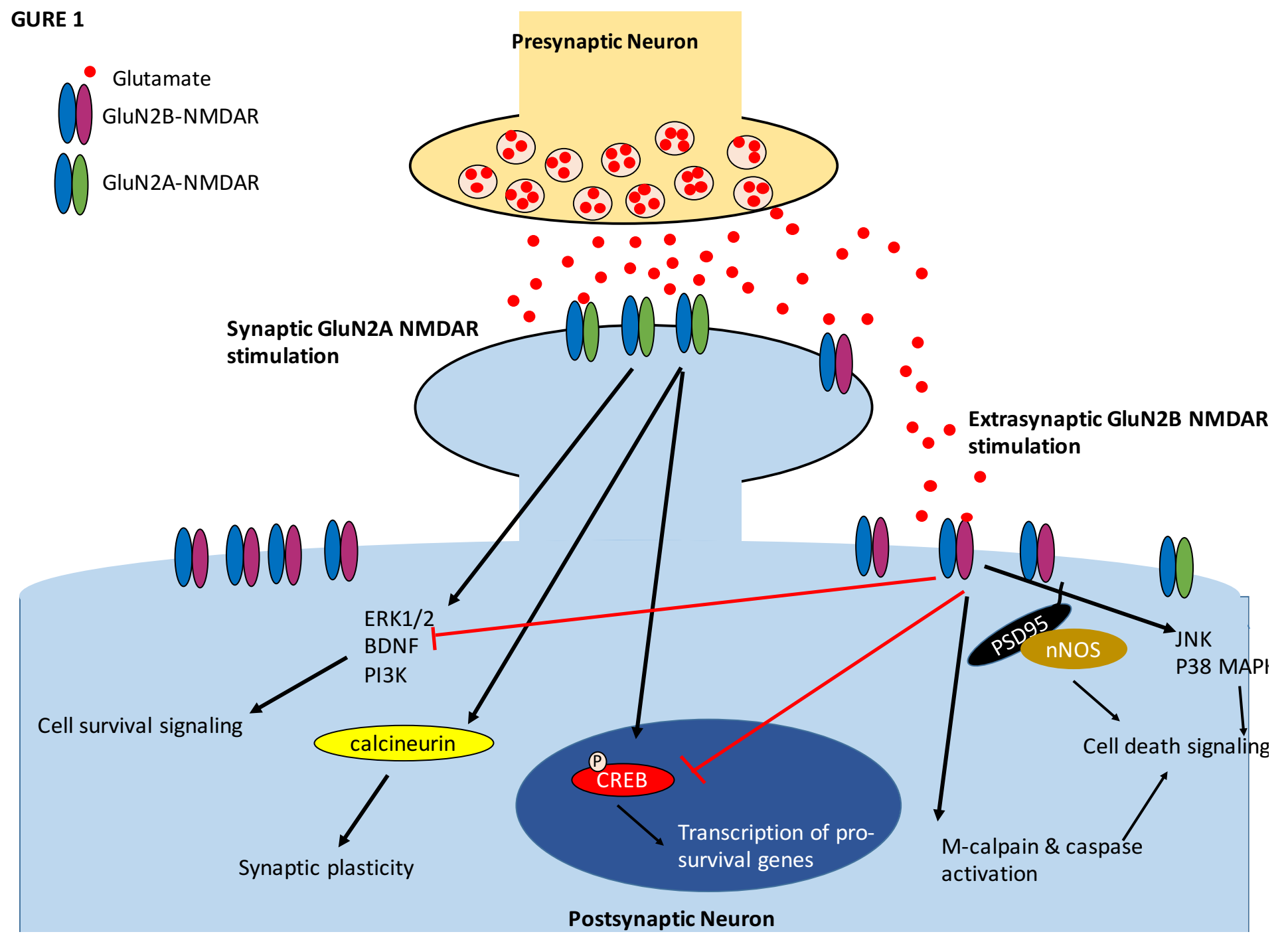


FIGURE 2

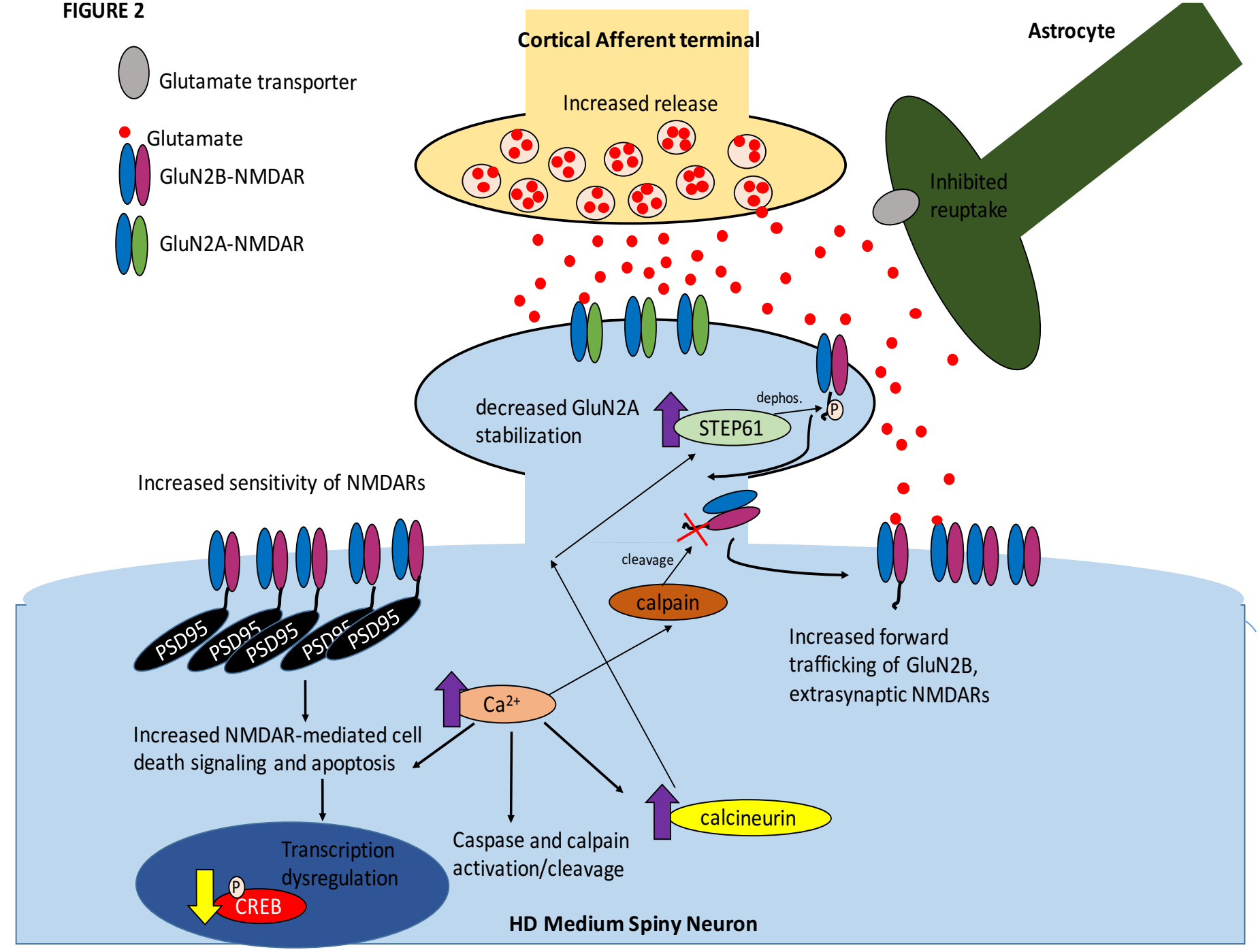

